\title{
Atorvastatin has a protective effect in a mouse model of bronchial asthma through regulating tissue transglutaminase and triggering receptor expressed on myeloid cells-1 expression
}

\author{
MING-WEI LIU ${ }^{1 *}$, RONG LIU $^{1 *}$, HAI-YING WU ${ }^{1}$, MEI CHEN $^{2}$, MIN-NA DONG $^{1}$, \\ YUN-QIAO HUANG ${ }^{1}$, CHUN-HAI ZHANG $^{1}$, YIN-ZHONG WANG ${ }^{1}$, JING XIA ${ }^{1}$, YANG SHI ${ }^{1}$, \\ FENG-MEI XIE ${ }^{3}$, HUA LUO $^{1}$, XIN-YUAN ZHAO $^{1}$, WEI WEI ${ }^{1}$ and MEI-XIAN SU ${ }^{4}$ \\ ${ }^{1}$ Department of Emergency, The First Hospital Affiliated to Kunming Medical University, Kunming, Yunnan 650032; \\ ${ }^{2}$ Department of Respiratory Medicine, The Yan'An Hospital Affiliated to Kunming Medical University, \\ Kunming, Yunnan 650051; Departments of ${ }^{3}$ Gastroenterology and ${ }^{4}$ Emergency, \\ The Second Hospital Affiliated to Kunming Medical University, Kunming, Yunnan 650106, P.R. China
}

Received January 5, 2016; Accepted January 26, 2017

DOI: $10.3892 / \mathrm{etm} .2017 .4576$

\begin{abstract}
Airway remodeling in asthma contributes to airway hyperreactivity, loss of lung function and persistent symptoms. Current therapies do not adequately treat the structural airway changes associated with asthma. Statin drugs have improved respiratory health and their therapeutic potential in asthma has been tested in clinical trials. However, the mechanism of action of statins in this context has remained elusive. The present study hypothesized that atorvastatin treatment of ovalbumin-exposed mice attenuates early features of airway remodeling via a mevalonate-dependent mechanism. BALB/c mice were sensitized with ovalbumin and atorvastatin was delivered
\end{abstract}

Correspondence to: Professor Wei Wei, Department of Emergency, The First Hospital Affiliated to Kunming Medical University, 295 Xichang Road, Kunming, Yunan 650032, P.R. China

E-mail: 13808790610@139.com

Professor Mei-Xian Su, Department of Emergency, The Second Hospital Affiliated to Kunming Medical University, 1 Mayuan Road, Kunming, Yunnan 650106, P.R. China

E-mail:1mhs21@public.km.yn.cn

*Contributed equally

Abbreviations: TREM-1, triggering receptor expressed on myeloid cells 1; BHR, bronchial hyperresponsiveness; tTG, tissue transglutaminase; VEGF, vascular endothelial growth factor; NF- $\kappa \mathrm{B}$, nuclear factor kappa B; MMP-9, matrix metalloproteinase 9; DEX, dexamethasone; $\alpha$-SMA, smooth muscle actin- $\alpha$; NQO1, NADPH quinine oxidoreductase; Nrf2, nuclear factor erythroid 2-related factor 2 ; HIF-1 $\alpha$, hypoxia-inducible factor $1 \alpha$; TGF- $\beta$, transforming growth factor $\beta$; BALF, bronchoalveolar lavage fluid

Key words: atorvastatin, tissue transglutaminase, triggering receptor expressed on myeloid cells 1, matrix metalloproteinase, airway remodeling, mice via oral gavage prior to each ovalbumin exposure. Reverse transcription-semi-quantitative polymerase chain reaction (RT-semi-qPCR), ELISA and western blot analysis were used to assess the expression of a number of relevant genes, including tissue transglutaminase (tTG), triggering receptor expressed on myeloid cells (TREM)-1, nuclear factor erythroid 2-related factor (Nrf) 2, hypoxia-inducible factor (HIF)- $1 \alpha$, transforming growth factor (TGF)- $\beta 1$, matrix metalloproteinase (MMP)-9 and tissue inhibitors of metalloproteinases (TIMP)-1 in lung tissue. $\alpha$-Smooth muscle actin ( $\alpha$-SMA) activity was measured by immunohistochemistry. Airway hyperresponsiveness, lung collagen deposition, airway wall area, airway smooth muscle thickness and lung pathology were also assessed. Atorvastatin treatment led to downregulation of TTG and TREM-1 expression in lung tissue after ovalbumin sensitization, blocked the activity of MMP-9, vascular endothelial growth factor, nuclear factor- $\kappa$ B p65, $\alpha$-SMA, HIF- $\alpha$ and TGF- $\beta 1$ and up-regulated Nrf2 expression. Furthermore, the number of lymphocytes and eosinophils in the atorvastatin group was significantly lower than that in the control group. In addition, airway hyperresponsiveness, lung collagen deposition, airway wall area, airway smooth muscle thickness and pathological changes in the lung were significantly decreased in the atorvastatin group, and tumor necrosis factor- $\alpha$, interleukin (IL)-8, IL-13 and IL-17 in serum were significantly decreased. Histological results demonstrated the attenuating effect of atorvastatin on ovalbumin-induced airway remodeling in asthma. In conclusion, the present study indicated that atorvastatin significantly alleviated ovalbumin-induced airway remodeling in asthma by downregulating tTG and TREM-1 expression. The marked protective effects of atorvastatin suggest its therapeutic potential in ovalbumin-induced airway remodeling in asthma treatment.

\section{Introduction}

Bronchial remodeling involves a series of chronic injuries in airway wall cells and repair processes characterized by 
variations in the cellular composition, quantity and structure. It mainly manifests as extracellular matrix (ECM) deposition, basement membrane thickening, airway smooth muscle (ASM) hyperplasia and hypertrophy (1-3). Bronchial remodeling is the pathological basis for chronicity, sustainability, and exacerbation of bronchial remodeling (3). It is the pathological basis for irreversible bronchial obstruction as well as steroid-resistant asthma (4). Consequently, inhibition of bronchial remodeling is an attractive target to facilitate control of the occurrence and development of bronchial asthma.

Transglutaminase 2, also known as tissue transglutaminase (tTG) (5), is a member of the transglutaminase family $(5,6)$. tTG is a predominantly cytoplasmic protein which is also detectable in the nucleus, plasma membrane and ECM (5). tTG can post-translationally modify ECM proteins to form stable structures, which are resistant to degradation, thus leading to ECM protein deposition as well as tissue fibrosis (6-8). The content and activity of tTG protein is markedly increased in renal interstitial fibrosis in animal models and diseased kidney tissue samples (9). Consequently, tTG is considered an important regulatory protein in tissue fibrosis and remodeling. However, the specific mechanism has remained to be clarified and requires further study.

Triggering receptor expressed on myeloid cells-1 (TREM-1) is mainly expressed in neutrophils, granulocytes and monocytes/giant cells (10). Under conditions of infection and inflammation, the expression levels of TREM-1 are significantly upregulated (11). Activation of TREM-1 not only mediates genetic transcription of pro-inflammatory cytokines, chemokine receptors and cell surface molecules (12), but also increases the generation of cytokines [tumor necrosis factor (TNF)- $\alpha$, interleukin (IL)-1 $\beta$ and IL-6] through the synergistic activation of Toll-like receptors and Nod-like receptors (12).

Atorvastatin is a 3-hydroxy-3-methyl-glutaryl-coenzyme A (HMG-CoA) reductase inhibitor. It can inhibit the transformation of HMG-CoA to hydroxyvaleric acid (MA), the precursor of isoprene. Metabolites of MA, including, farnesyl diphosphate (FPP) and geranylgeranyl pyrophosphate (GGPP), not only act as cholesterol precursors (13), but also participate in the activation of small G-proteins of the Ras and Rho protein family. FPP and GGPP mainly participate in the generation of inflammation as well as cell proliferation and migration, macrophage phagocytosis and small vessel leakage $(13,14)$. They also promote the release of transforming growth factor (TGF)- $\beta 1$, vascular endothelial growth factor (VEGF) and matrix metalloproteinases (MMPs) and the expression of nitric oxide synthase-2, and activate the nuclear factor $(\mathrm{NF})-\kappa \mathrm{B}$ pathway $(15,16)$. Therefore, it is speculated that atorvastatin may inhibit bronchial remodeling in bronchial asthma in mice.

The present study found that atorvastatin inhibited the expression of tTG, reduced the activity of Smad3/TGF- $\beta$ and collagen deposition, and improved the remodeling of lung tissue in mice with bronchial asthma. Atorvastatin reduced the expression of NF- $\mathrm{KB}$ p65, increased the expression of nuclear factor erythroid 2-related factor ( $\mathrm{Nrf}$ )2, and reduced tracheal inflammation and peroxidative reactions through inhibition of the expression of TREM-1. It also decreased the expression of MMP-9 and TGF- $\beta 1$, and inhibited lung tissue remodeling in mice with bronchial asthma.

\section{Materials and methods}

Chemicals and reagents. Ovalbumin (OVA; grade V) and dexamethasone (Dex) were purchased from Sigma-Aldrich (Merck KGaA, Darmstadt, Germany). Atorvastatin was purchased from Pfizer (New York City, NY, USA). Aluminum hydroxide was obtained from Pierce (Thermo Fisher Scientific, Inc., Waltham, MA, USA). The TGF- $\beta 1$ ELISA kit was from R\&D Systems (Minneapolis, MN, USA).

Animals. Six-week-old female BALB/c mice were purchased from the Kunming Medical University Animal Center (Kunming, China) and bred in-house. All experimental procedures were approved by the Animal Care and Use Committee of Kunming Medical University. The experimental procedures were approved by the Ethics Committee of Kunming Medical University (Kunming, China).

Murine model of chronic asthma. The model was established according to a protocol by Jain et al (17). In brief, mice were sensitized by means of intraperitoneal injection of OVA $(10 \mu \mathrm{g})$ precipitated with aluminum hydroxide $(100 \mu \mathrm{g})$ on days 0 and 14 . Subsequently, mice were given $1.5 \mathrm{mg} / \mathrm{kg}$ atorvastatin (atorvastatin group or treatment group) by oral gavage, $10 \mathrm{mg} / \mathrm{kg}$ Dex (Dex group) or $0.2 \mathrm{ml}$ phosphate-buffered saline (PBS) by means of intraperitoneal injection $0.5 \mathrm{~h}$ prior to each OVA challenge (nebulized $2.5 \%$ solution $30 \mathrm{~min} / \mathrm{day}$, 3 days/week for 6 weeks). Mice were sacrificed $24 \mathrm{~h}$ after the final OVA inhalation. Control groups were intraperitoneally injected with PBS and inhaled aerosolized PBS at the same time as the other three groups. Mice treated with atorvastatin or Dex but without OVA sensitization were also set up as controls. Serum was collected on day 21 and airway hyperresponsiveness (AHR) [enhanced pause (Penh)] to increasing concentrations of methacholine (MCh; $1.5-12 \mathrm{mg} / \mathrm{ml}$; Hubei Dongshang Chemical Co., Ltd., Hubei, China) was measured by whole-body plethysmography (Buxco Research Systems, Wilmington, NC, USA) on day 22 (17). Lungs were used either for bronchoalveolar lavages (BALs) and protein extraction or for histological analyses and RNA extraction.

Extraction of RNA. For the isolation of RNA from lung tissue, mice were sacrificed via an overdose of sodium pentobarbital (intravenous injection, $150 \mathrm{mg} / \mathrm{kg}$; Wuhan Dinghui Chemical Co., Ltd, Wuhan, China) and under aseptic conditions the lung tissues were removed and immediately frozen in liquid nitrogen. Prior to RNA extraction, lung samples were homogenized in TRIzol reagent (Thermo Fisher Scientific, Inc.) using a Mixer 301 (Invitrogen; Thermo Fisher Scientific, Inc.). Total RNA was extracted according to the manufacturer's instructions. RNA samples were electrophoresed in agarose gel (Shanghai Yuanye Biochemicals Ltd. Shanghai, China) and the gel image visualized using Kodak 1D software (Life Technologies, Grand Island, NY, USA), with ethidium bromide (Beijing Xin Hua Luyuan Science and Technology Co., Ltd, Beijing, China) for quality control.

Reverse-transcription semi-quantitative polymerase chain reaction analysis ( $R T$-semi-qPCR). Three micrograms of RNA were reverse-transcribed with 200 U Moloney Murine 
Table I. Primer sequences used for polymerase chain reaction.

\begin{tabular}{llc}
\hline Gene & \multicolumn{1}{c}{ Primer } & Product length (bp) \\
\hline tTG & F-5'-CAAGAACAAGGCAGACTTATCGC-3' & 400 \\
& R-5'-TCTGATTAT CTCGCACCAGGAAG-3' & 298 \\
TGF- $\beta 1$ & F-5'-CTGCTGACCCCCACTGATAC-3' & \\
MMP-9 & R-5'-CTGTATTCCGTCTCCTTGGTTC-3' & \\
& F-5'-GCAGGAGAGGAAGCTGAGCT-3' & 335 \\
TIMP-1 & R-5'-TCATGGTGAGAACCGAAGC-3' \\
& F-5'-TCCCCAGAAATCATCGAGAC-3' & 329 \\
& R-5'-ATGGCTGAACAGGGAAACAC-3' & 374 \\
\hline
\end{tabular}

tTG, tissue transglutaminase; MMP-9, matrix metalloproteinase 9; TGF- $\beta$, transforming growth factor $\beta$; TIMP-1, tissue inhibitors of metalloproteinases 1; F, forward; R, reverse.

Leukemia Virus reverse transcriptase (Shanghai Jiang Lai Biotechnology Co., Ltd., Shanghai, China) for $1 \mathrm{~h}$ at $37^{\circ} \mathrm{C}$ for synthesis of complementary (c)DNA. Quantitative changes in mRNA expression were assessed by semi-qPCR in a Bio-Rad CFX (Bio-Rad Laboratories, Inc., Hercules, CA, USA) using SYBR Green PCR Master Mix (Aria-tous, Isfahan, Iran). The PCR reaction mix was made up by $0.5 \mathrm{U}$ of Taq polymerase, $2 \mu \mathrm{l}$ of each primer and $3 \mu \mathrm{l}$ of each cDNA sample in a final volume of $20 \mu \mathrm{l}$. Conditions for amplification were 1 cycle at $94^{\circ} \mathrm{C}$ for $5 \mathrm{~min}$ followed by 40 cycles of $94^{\circ} \mathrm{C}$ for $30 \mathrm{sec}, 58^{\circ} \mathrm{C}$ for $30 \mathrm{sec}$ and $70^{\circ} \mathrm{C}$ for $45 \mathrm{sec}$. All amplifications were repeated three times. Oligonucleotide primer sequences (Santa Cruz Biotechnology, Inc., Dallas, TX, USA) are listed in Table I. $\beta$-actin was used as an endogenous control. The mRNA levels of various genes were quantified using SYBR premix Ex Taq (Takara Bio, Inc., Otsu, Japan), and analysis was performed using an ABI PRISM 7300 RT-PCR System (Applied Biosystems; Thermo Fisher Scientific, Inc.). Ordinary PCR products were separated on a $2 \%$ agarose gel. Expressions were normalized to endogenous controls. Relative quantification of mRNA expression levels of target genes was calculated using the $2^{-\Delta \Delta \mathrm{Cq}}$ method (18).

Western blot analysis. Lung tissues were homogenized in lysis buffer containing protease inhibitors and protein concentrations were determined using the Bradford method (Bio-Rad Laboratories Inc.). A total of $50 \mu \mathrm{g}$ protein from each sample was subjected to $15 \%$ SDS-PAGE at $120 \mathrm{~V}$ for $90 \mathrm{~min}$ and separated proteins were transferred onto polyvinylidene difluoride membranes (GE Healthcare, Little Chalfont, UK) by the wet transfer method (250 mA, $90 \mathrm{~min}$ ). Nonspecific sites were blocked with $5 \%$ non-fat dry milk in Tris-buffered saline with Tween-20 (25 mM Tris, pH 7.5, 150 mM NaCl, 0.1\% Tween-20) for $1 \mathrm{~h}$, and the blots were then incubated overnight at $4{ }^{\circ} \mathrm{C}$ with anti-TGF- $\beta 1$ antibody (1:2,000; cat. no. sc-47778 B; Cell Signaling Technology Inc., Beverly, MA, USA), anti-Nrf2 antibody (1:2,000; cat. no. ab137550; Sigma-Aldrich; Merck $\mathrm{KGaA}$ ), anti-NADPH quinine oxidoreductase (NQO1) antibody (1:1,000; cat. no. AF7567; R\&D Systems, Inc., Minneapolis, MN, USA), anti-TREM-1 antibodies (1:1,000; cat. no. 3672; Santa Cruz Biotechnology, Inc.), anti-VEGF antibody (1:2,000; cat. no. sc-152; Santa Cruz Biotechnology, Inc.), anti-hypoxia-inducible factor (HIF)-1 $\alpha$ antibody (1:2,000; cat. no. ab114977; Serotec Ltd., Oxford, UK), anti-phosphorylated

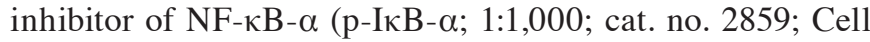
Signaling Technology, Inc.), anti-NF- $\mathrm{B}$ p65 (1:1,000; cat. no. 9936; Cell Signaling Technology, Inc.) anti-tTG antibody (1:2,000; cat. no. SG203351; BD Biosciences, Franklin Lakes, NJ, USA) and anti-phosphorylated (p)-Smad3 (1:2,000; cat. no. sc-130218; Santa Cruz Biotechnology, Inc.). Subsequently, samples were incubated for $2 \mathrm{~h}$ at room temperature with anti-rabbit horseradish peroxidase (HRP)-conjugated immunoglobulin G (IgG; 1:2,000; cat. no. sc-2749; Santa Cruz Biotechnology, Inc.) or anti-mouse HRP-conjugated IgG (1:4,000; cat. no. 7076; Amersham Pharmacia Biotech, Piscataway, NJ, USA) to detect binding of antibodies. The membranes were stripped and reblotted with an anti-actin antibody (1:2,000; cat. no. A2228; Sigma-Aldrich; Merck KGaA) to verify equal loading of protein in each lane. The binding of the specific antibodies was visualized by exposing to photographic film (SynGene; Synoptics Ltd., Cambridge, UK) after treatment with an electrochemiluminescence detection reagent (Wellstat M1M; cat. no. 310806; PerkinElmer, Inc., Waltham, MA, USA).

Immunohistochemical detection of $\alpha$-SMA. Lungs were inflation fixed at a constant pressure $\left(25 \mathrm{~cm} \mathrm{H}_{2} \mathrm{O}\right)$ by tracheal installation of $4 \%$ paraformaldehyde, transferred to $70 \%$ ethanol after $24 \mathrm{~h}$ and embedded in paraffin as previously described (19). Immunostaining was performed on lung sections after antigen retrieval using Retrievagen A (Zymed, San Francisco, CA, USA) at $100^{\circ} \mathrm{C}$ for $20 \mathrm{~min}$, and quenching endogenous peroxidases with $3 \% \mathrm{H}_{2} \mathrm{O}_{2}$. Sections were blocked with $2 \%$ bovine serum albumin in PBS, followed by staining with primary anti- $\alpha$-SMA $(1: 2,000$; cat. no. 11475 ; BD Pharmingen, San Jose, CA, USA) at room temperature for $1 \mathrm{~h}$. Sections were washed and after application of the goat HRP-conjugated anti-rabbit IgG secondary antibody (1:4,000; cat. no. HAF109; R\&D Systems), tissues were developed using Vectastain ABC (Vector Labs, Burlingame, CA, USA) 
and 3,3'-diaminobenzidine (Vector Labs). After staining, five high-power fields (magnification, $\mathrm{x} 400$ ) were randomly selected in each slide, and the average proportion of cells with positive expression in each field was counted using the true color multi-functional cell image analysis management system (Beckman Coulter, Inc, Fullerton, CA, USA), with values expressed as positive units (pu).

Measurement of AHR. AHR to MCh was determined on day 33 by single-chamber body plethysmography as described previously (20). In brief, each mouse was placed in the Buxco single chamber, acclimatized for 5-10 $\mathrm{min}$ and baseline recordings were made for $5 \mathrm{~min}$. The mice were then challenged with PBS or various concentrations of $\mathrm{MCh}$ aerosol and signals were recorded with in-built software (Buxco) to determine the Penh values, which are reliable in BALB/c mice (20). MCh PC200, which is the partial concentration of MCh required to double the baseline Penh, Penh0, was then calculated. To confirm the findings of the non-invasive body plethysmography, respiratory mechanics were determined during mechanical ventilation (FlexiVent System; Scireq, Montréal, Canada) as previously described (20). In brief, following anesthetisia via intraperitoneal administration of sodium pentobarbital $(90 \mathrm{mg} / \mathrm{kg}$; Wuhan Dinghui Chemical Co., Ltd.) mice were intubated after tracheostomy, ventilated with a computer-controlled ventilator, and airway resistance with various concentrations of MCh was estimated using the flexiVent system (Scireq) that integrates the ventilator with the respiratory mechanics.

ELISA. At $24 \mathrm{~h}$ after the last challenge, bronchoalveolar lavage fluid (BALF) was obtained from the mice under anaesthesia with intravenous injection of sodium pentobarbital $(60 \mathrm{mg} / \mathrm{kg})$, using $1 \mathrm{ml}$ sterile isotonic saline. Lavage was performed four times in each mouse and the total volume was collected separately. The lavage fluid sample was immediately centrifuged at $2,000 \mathrm{x} \mathrm{g}$ for $10 \mathrm{~min}$ at room temperature and stored at $-80^{\circ} \mathrm{C}$ until use. The concentrations of IL-8, IL-13, IL-17, TNF- $\alpha$, MMP-9 and TIMP-1 in BALF supernatants were assayed by ELISA (mouse IL-8 ELISA kit, cat. no. 20760, Bio-Medical Assay Co., Ltd., Beijing, China; mouse IL-13 ELISA kit, cat. no. KMC2222; mouse IL-17 ELISA kit, cat. no. KMC3022; mouse TNF- $\alpha$ ELISA kit, cat. no. KMC3011, all Thermo Fisher Scientific, Inc.; mouse MMP-9 ELISA kit, cat. no. M0238, Bio-Medical Assay Co., Ltd.; mouse TIMP-1 ELISA kit, cat. no. EMTIMP1CL, Thermo Fisher Scientific, Inc.) according to the manufacturer's instructions.

Inflammatory cell counts in BALF. Following OVA challenge of mice, BALF samples were obtained and processed, and inflammatory cells were counted as previously described (21). In brief, at $48 \mathrm{~h}$ after the last challenge, mice were given an intraperitoneal injection of pentobarbital $(50 \mathrm{mg} / \mathrm{kg}$; Hanlim Pharm. Co., Seoul, Korea) and a tracheostomy was performed. To obtain BALF, ice-cold PBS $(0.6 \mathrm{ml})$ was infused into the lung and withdrawn via tracheal cannulation three times (total volume, $1.8 \mathrm{ml}$ ). Total inflammatory cell numbers were assessed by counting cells in at least five squares of a hemocytometer after exclusion of dead cells by Trypan blue staining. To determine differential cell counts, $100 \mathrm{ml}$ of BALF was centrifuged onto slides $\left(200 \times \mathrm{g}, 4^{\circ} \mathrm{C}, 10 \mathrm{~min}\right)$ using a Cytospin
(Hanil Science Industrial, Seoul, Korea). After slides were dried, cells were fixed and stained using DiffQuikH staining reagent (B4132-1A; IMEB Inc., Deerfield, IL, USA), according to the manufacturer's instructions. The supernatant of the BALF was stored at $27^{\circ} \mathrm{C}$ for cytokine measurements.

Measurement of intracellular reactive oxygen species (ROS). ROS were measured as previously described (22). BALF cells were washed with PBS. To measure intracellular ROS, cells were incubated for $10 \mathrm{~min}$ at room temperature with PBS containing $3.3 \mu \mathrm{M} \mathrm{2}$ ',7'-dichlorofluorescein (DCF) diacetate (Molecular Probes, Eugene, OR, USA), to label intracellular ROS. DCF-stained cells $\left(1 \times 10^{4}\right)$ were subjected to fluorescence-activated cell sorting analysis to measure ROS levels using a FACSCalibur instrument (BD Biosciences, San Jose, CA, USA). The data were analyzed with CellQuest Pro 3.3 software (BD Biosciences).

Measurement of glutathione (GSH) in lung tissues. Lung tissues were homogenized with $10 \mathrm{ml}$ ice-cold lysis buffer (50 $\mathrm{mM}$ phosphate buffer containing $1 \mathrm{mM}$ ethylene diamine tetraacetic acid) per gram tissue. After centrifugation at $10,000 \times \mathrm{g}$ for $15 \mathrm{~min}$ at $4^{\circ} \mathrm{C}$, the supernatants were removed, deproteinated and then stored at $-20^{\circ} \mathrm{C}$ until the samples were assayed. Total GSH and GSH disulfide levels were determined using a GSH Assay kit (Cayman Chemical Co., Ann Arbor, MI, USA) according to the manufacturer's protocol.

Collagen analysis. Collagen content was measured in lung tissue homogenates by a biochemical assay according to the manufacturer's instructions (Sircol collagen assay, Biocolor, Carrickfergus, Northern Ireland). Lung tissue (100 mg) was homogenized in $1 \mathrm{ml}$ Tris buffer containing $1 \mathrm{M}$ sodium chloride and a protease inhibitor cocktail (Sigma-Aldrich; Merck-Millipore KGaA, Darmstadt, Germany). Samples were incubated overnight at $4^{\circ} \mathrm{C}$ with stirring and then centrifuged, and the supernatant was assayed (23).

Hydroxyproline (Hyp) determination. As an indirect measure of tissue collagen content, Hyp levels in lung tissue (100 mg) were determined according to a modified method described by Jamall et al (24). The Hyp content was expressed in micrograms of Hyp per gram of wet weight $(\mu \mathrm{g} / \mathrm{g})$. The number of Hyp measurements was the same as the number of animals in each group.

Histopathology. After lavage, lungs were removed and fixed in paraformaldehyde, and tissue blocks were embedded in paraffin. Lung sections underwent deparaffinization and hydration for staining. Hematoxylin and eosin (H\&E) staining was used to evaluate ASM thickness and the airway wall area (25). Sections were stained with Masson Trichrome stain to evaluate collagen deposition. Images of airway sections were randomly obtained at a magnification of x 20 with an RT Color Digital camera (Diagnostic Instruments, Sterling Heights, MI, USA). Airways with a ratio of maximum to minimum internal diameter of no less than 2 were considered as cut obliquely and were not included $(25,26)$. In brief, five images were analyzed per section by using Image Pro-Plus software 6.0 (Media Cybernetics, Rockville, MD, USA) calibrated with a reference 


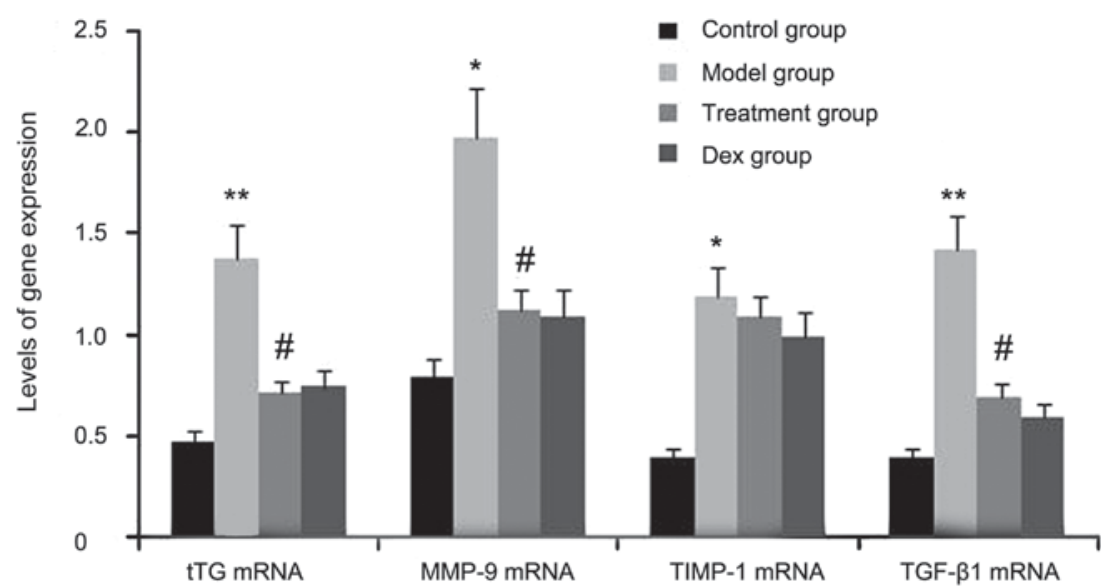

Figure 1. Effects of atorvastatin treatment on tTG, TIMP-1, TGF- $\beta 1$ and MMP-9 gene expression in the lung tissues of asthmatic mice. Mice were treated with atorvastatin or Dex and challenged with OVA (nebulized 2.5\% solution $30 \mathrm{~min} / \mathrm{day}, 3$ days/week for 6 weeks). The mRNA levels of tTG, TIMP-1, TGF- $\beta 1$ and MMP-9 were determined by reverse-transcription quantitative PCR analysis. Values are expressed as the mean \pm standard deviation of one experiment consisting of three replicates. " $\mathrm{P}<0.05,{ }^{* *} \mathrm{P}<0.01$, vs. control group. ${ }^{*} \mathrm{P}<0.05$ vs. model group. PCR, polymerase chain reaction; tTG, tissue transglutaminase; MMP-9, matrix metalloproteinase 9; TGF- $\beta$, transforming growth factor $\beta$; TIMP-1, tissue inhibitors of metalloproteinases 1; Dex, dexamethasone.
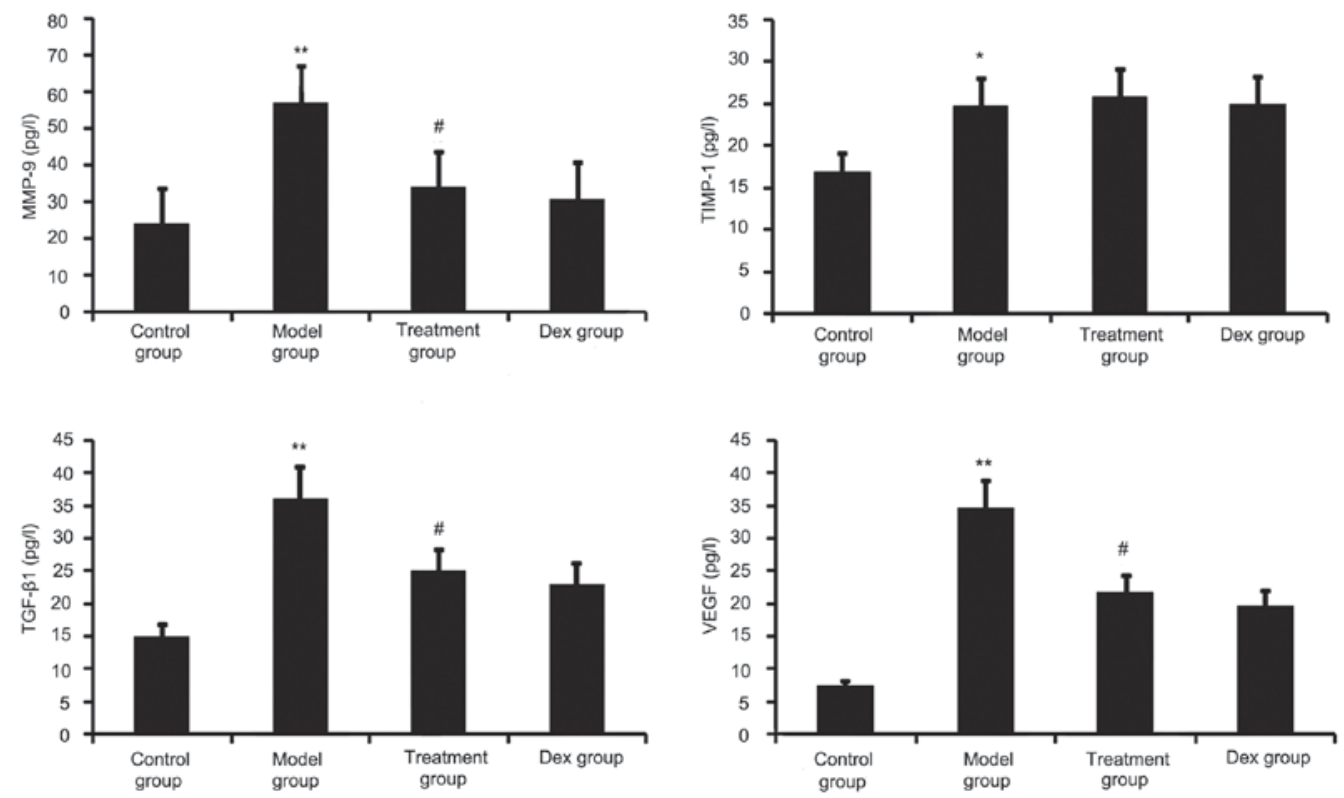

Figure 2. Effects of atorvastatin treatment on the levels of TGF- $\beta 1$, VEGF, MMP-9 and TIMP-1 in the BALF of asthmatic mice. Mice were treated with atorvastatin or Dex and challenged with OVA (nebulized 2.5\% solution $30 \mathrm{~min} /$ day, 3 days/week for 6 weeks) and the BALF levels of TGF- $\beta 1$, VEGF, MMP-9 and TIMP-1 proteins were measured by ELISA. Values are expressed as the mean \pm standard error of the mean. ${ }^{*} \mathrm{P}<0.05,{ }^{* *} \mathrm{P}<0.01$ vs. control group; ${ }^{*} \mathrm{P}<0.05$ vs. model group. MMP-9, matrix metalloproteinase 9; VEGF, vascular endothelial growth factor; TGF- $\beta$, transforming growth factor $\beta$; TIMP-1, tissue inhibitors of metalloproteinases 1; Dex, dexamethasone; BALF, bronchoalveolar lavage fluid.

micrometer slide. For airway wall area measurement, the basement membrane perimeter $(\mathrm{Pbm})$ and total wall area (WAt) were measured at a magnification of $\mathrm{x} 400$. The airway wall area was normalized to $\mathrm{Pi}$ (WAt/ $\mathrm{Pbm}$ ) (26). ASM thickness in H\&E-stained lung sections was also evaluated by measuring the thickness of the smooth-muscle cell layer beneath the airway epithelial cell basement membrane (22). Collagen deposition was expressed as the area of Masson staining per micron length of the bronchiolar basement membrane.

Statistical analysis. Values are expressed as the mean \pm standard error of the mean. Statistical calculations were performed using GraphPad Prism 6.0 software (GraphPad Software, Inc.,
La Jolla, CA, USA). Significant differences among groups were identified by analysis of variance and Tukey's honest post-hoc test was used for individual comparisons. When variances were unequal, Welch's correction was applied. When only two groups were compared, a one- or two-tailed Student's t-test was applied as appropriate. $\mathrm{P}<0.05$ was considered to indicate a statistically significant difference.

\section{Results}

Atorvastatin blocks the expression of $t T G, M M P-9$ and TGF- $\beta 1$ in the lungs of OVA-induced asthmatic mice. The expression levels of tTG, TIMP-1, TGF- $\beta 1$ and MMP-9 were 

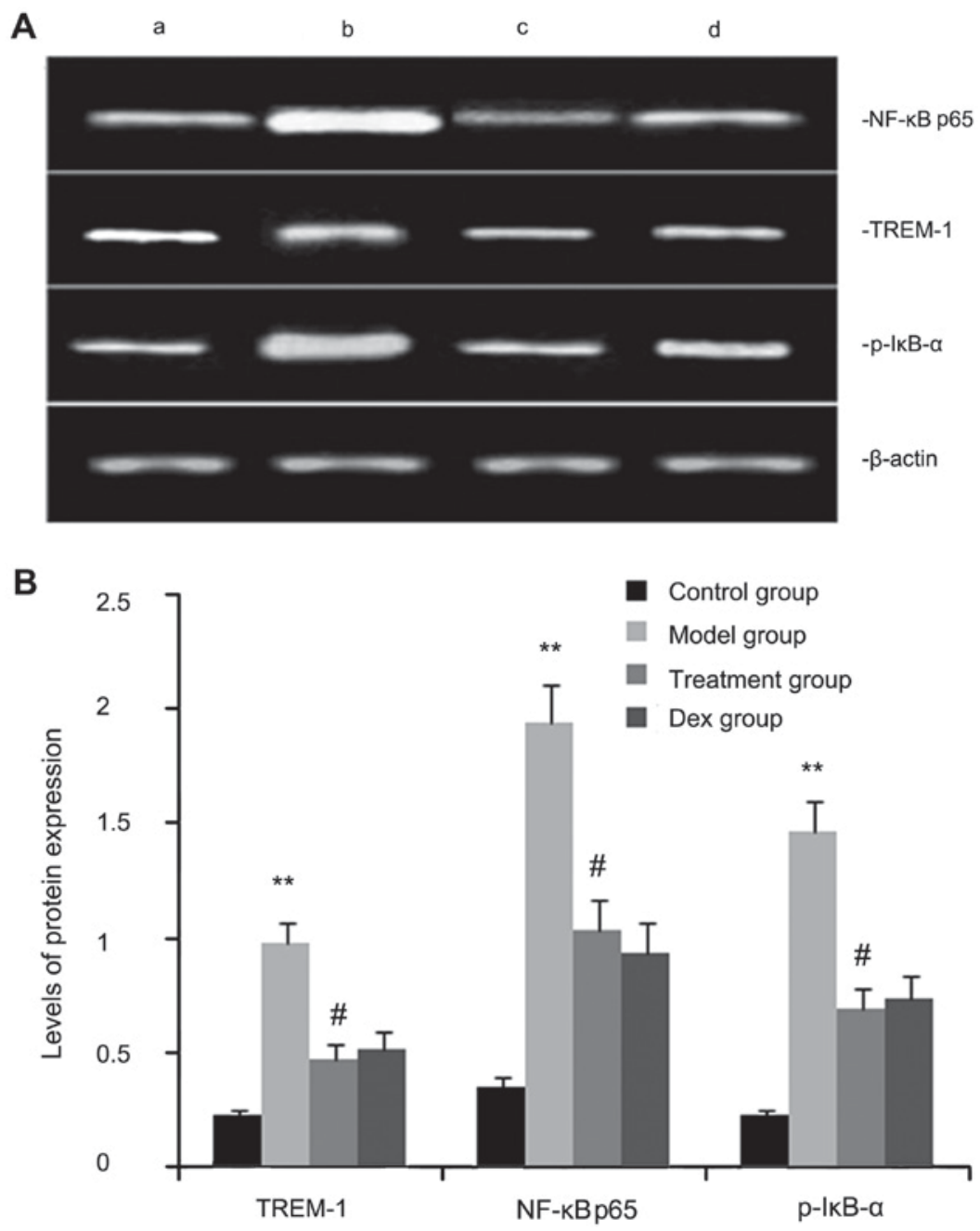

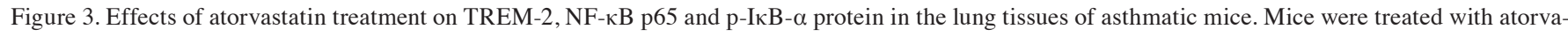
statin or Dex and challenged with ovalbumin (nebulized 2.5\% solution $30 \mathrm{~min} / \mathrm{day}, 3$ days/week for 6 weeks), and TREM-2, NF-kB p65 and p-IкB- $\alpha$ levels

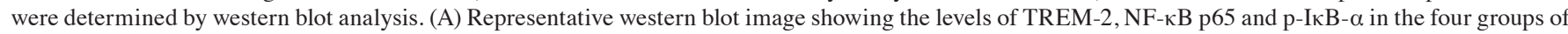
mice. Lanes: a, control group; b, model group; c, treatment group; d, Dex group. (B) Densitometrically quantified protein expression levels of TREM-2, NF-кB p65 and p-IкB- $\alpha$ in the four groups of mice. Values are expressed as the mean \pm standard error of the mean of one experiment consisting of three replicates. The experiments were performed in triplicate. ${ }^{* *} \mathrm{P}<0.01$ vs. control group. ${ }^{\#} \mathrm{P}<0.05$ vs. model group. NF- $\mathrm{kB}$, nuclear factor kappa $\mathrm{B}$; $\mathrm{p}$-IкB- $\alpha$, phosphorylated inhibitor of NF-kB alpha; Dex, dexamethasone; TREM-1, triggering receptor expressed on myeloid cells 1.

determined in atorvastatin-treated OVA-induced asthmatic mice by RT-semi-qPCR. As shown in Fig. 1, the gene expression levels of tTG, TIMP-1, TGF- $\beta 1$, and MMP-9 in lung tissues were markedly increased after OVA inhalation compared with the levels in the control mice. By contrast, the gene expression levels of tTG, TIMP-1, TGF- $\beta 1$ and MMP-9 in lung tissue were markedly suppressed by the treatment with atorvastatin and Dex. However, TIMP-1 mRNA expression in lung tissues was not significantly changed. No significant difference was observed between the atorvastatin group and the Dex group ( $\mathrm{P}>0.05)$.

Atorvastatin decreases TGF- $\beta 1, V E G F$ and MMP-9 in the BALF of OVA-induced asthmatic mice. TGF- $\beta 1$, VEGF, TIMP-1 and MMP-9 have a major role in airway remodeling in asthma; therefore, their levels in the BALF were assayed. As shown in Fig. 2, chronic OVA challenge induced a significant increase in the BALF levels of TGF- $\beta 1$, MMP-9, VEGF and TIMP-1. This increase was significantly reduced by atorvastatin treatment. However, TIMP-1 levels in the BALF were not significantly changed. No significant difference was observed between atorvastatin and Dex treatment in OVA-challenged mice.

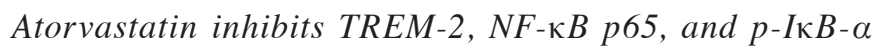
protein expression in OVA-induced asthmatic mouse lungs. The expression levels of TREM-2, NF-кB p65, and p-ІкB- $\alpha$ protein were determined by western blot analysis. As shown in

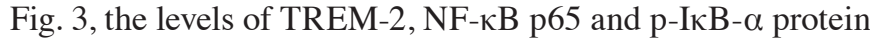
in lung tissues were markedly increased after OVA inhalation compared with those in the control mice. By contrast, the levels of TREM-2, NF- $\kappa \mathrm{B}$ p65 and $\mathrm{p}-\mathrm{I} \kappa \mathrm{B}-\alpha$ protein in lung tissue were markedly inhibited by treatment with atorvastatin and Dex. However, no significant difference was observed between the atorvastatin group and the Dex group $(\mathrm{P}>0.05)$.

Atorvastatin prevents inflammatory cell infiltration. The inflammatory nature of asthma is characterized by eosinophilia and can be visualized in the OVA-challenged lung. To determine whether atorvastatin reduces eosinophil infiltration and alleviates lung inflammation, the effect of atorvastatin treatment on 

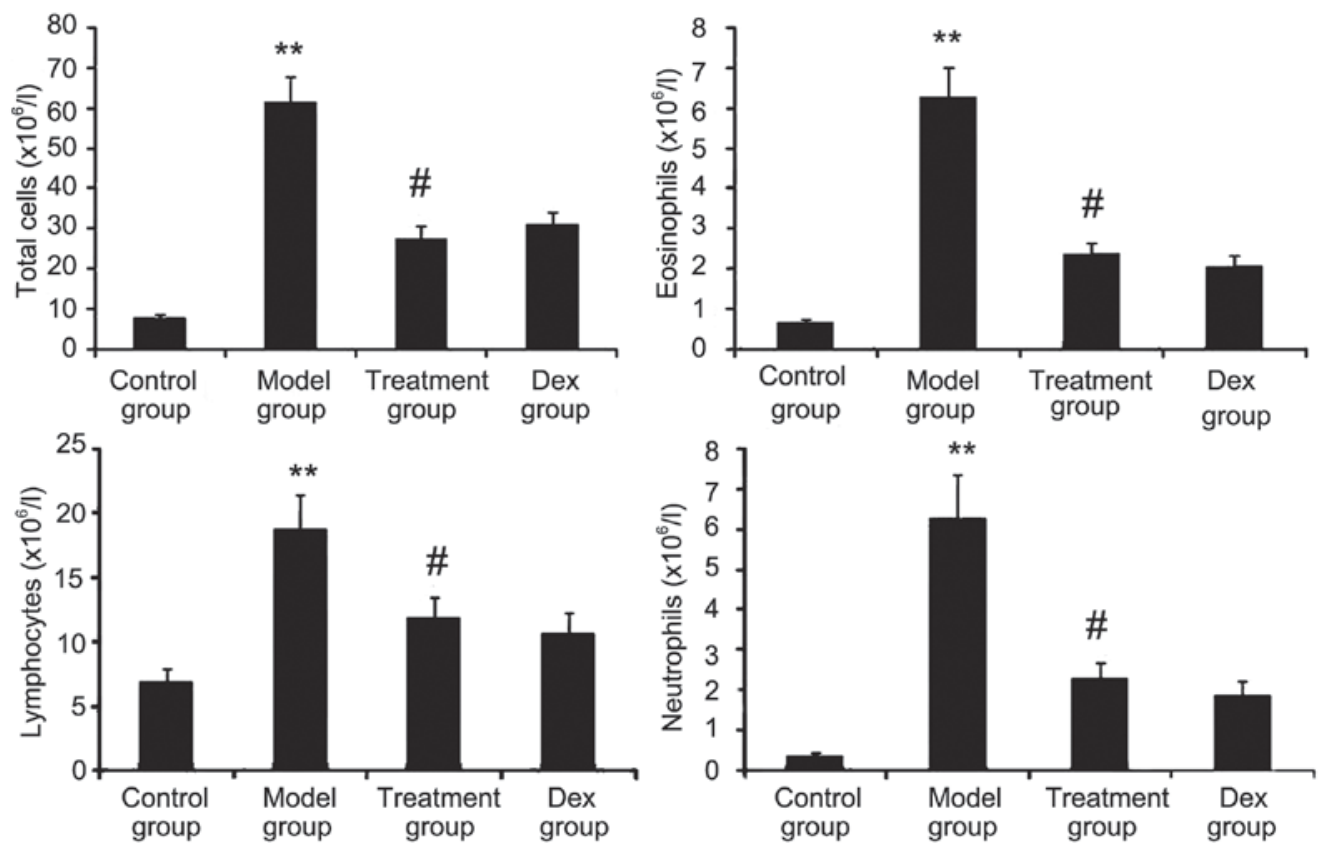

Figure 4. Effects of atorvastatin treatment on inflammatory cell infiltration in the lungs of PBS- or OVA-challenged mice. Mice were nebulized with PBS or OVA and treated with atorvastatin or Dex during the nebulization. To quantify inflammation in the bronchoalveolar lavage fluid, total inflammatory cells, eosinophils, lymphocytes and neutrophils were counted under a microscopy. Values are expressed as the mean \pm standard deviation of one experiment consisting of three replicates. The experiments were performed in triplicates. ${ }^{* *} \mathrm{P}<0.01$ vs. control group; ${ }^{*} \mathrm{P}<0.05$ vs. model group. Dex, dexamethasone; OVA, ovalbumin.
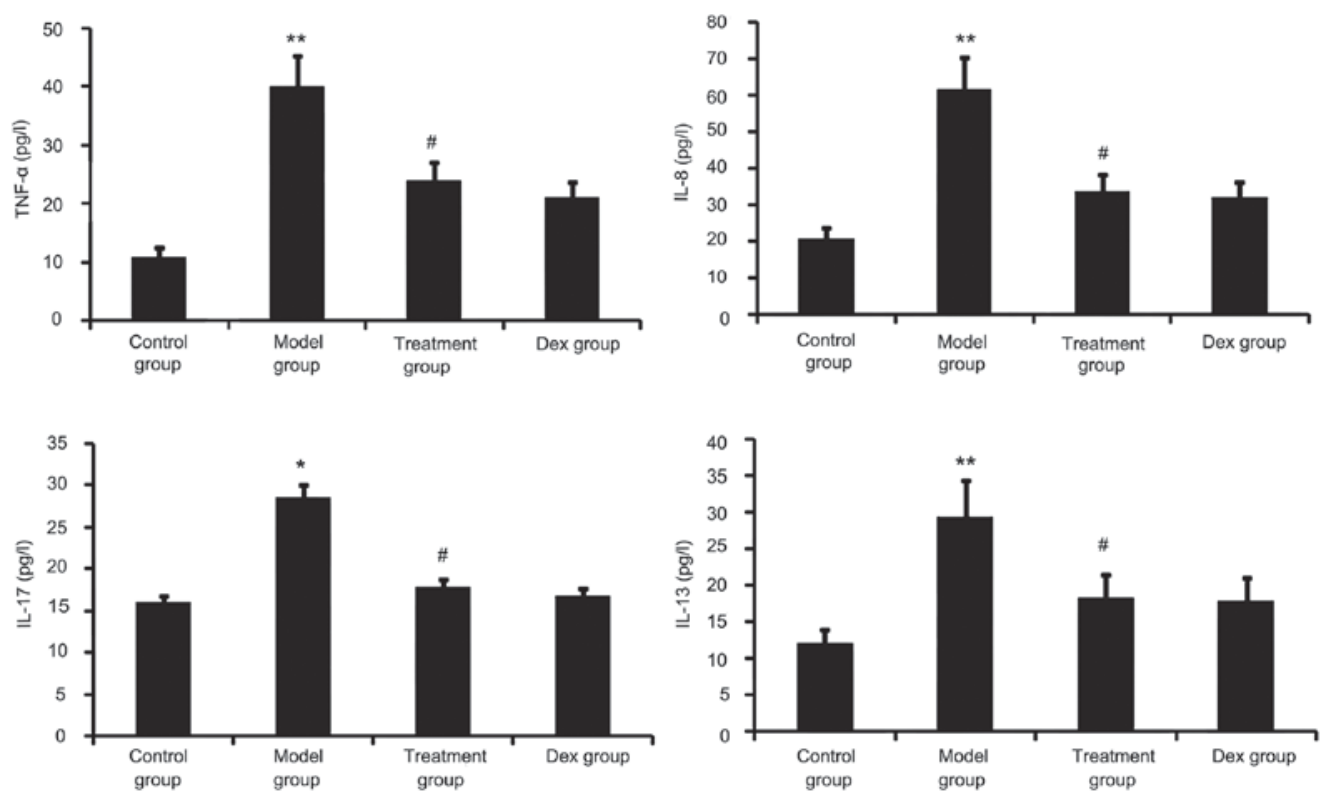

Figure 5. Effect of atorvastatin on lung inflammation. TNF- $\alpha$, IL-8, IL-13 and IL-17 in the bronchoalveolar lavage fluid were assayed by ELISA. Values are expressed as the mean \pm standard deviation of one experiment consisting of three replicates. The experiments were performed in triplicate. ${ }^{*} \mathrm{P}<0.05,{ }^{* * *} \mathrm{P}<0.01$, vs. control group; ${ }^{\#} \mathrm{P}<0.05$, vs. model group. Dex, dexamethasone; TNF, tumor necrosis factor; IL, interleukin.

overall lung inflammation was evaluated in OVA-challenged mice. Compared with that in PBS-challenged mice, the number of inflammatory cells in the BALF of OVA-challenged mice was found to be significantly increased (Fig. 4). Furthermore, atorvastatin administration significantly reduced the inflammatory cell recruitment and the number of eosinophils in OVA-challenged mice. No significant difference was observed between atorvastatin and Dex treatments in OVA-challenged mice.
Atorvastatin blocks lung inflammation. Airway tissue remodeling is thought to result from chronic repetitive injury to the airway wall caused by airway inflammation. As shown in Fig. 5, OVA challenge increased inflammatory mediators such as TNF- $\alpha$, IL-8, IL-13 and IL-17 in the BALF. However, this was significantly reduced in the atorvastatin and Dex treatment groups. No significant difference was observed between the atorvastatin group and the Dex group $(\mathrm{P}>0.05)$. 


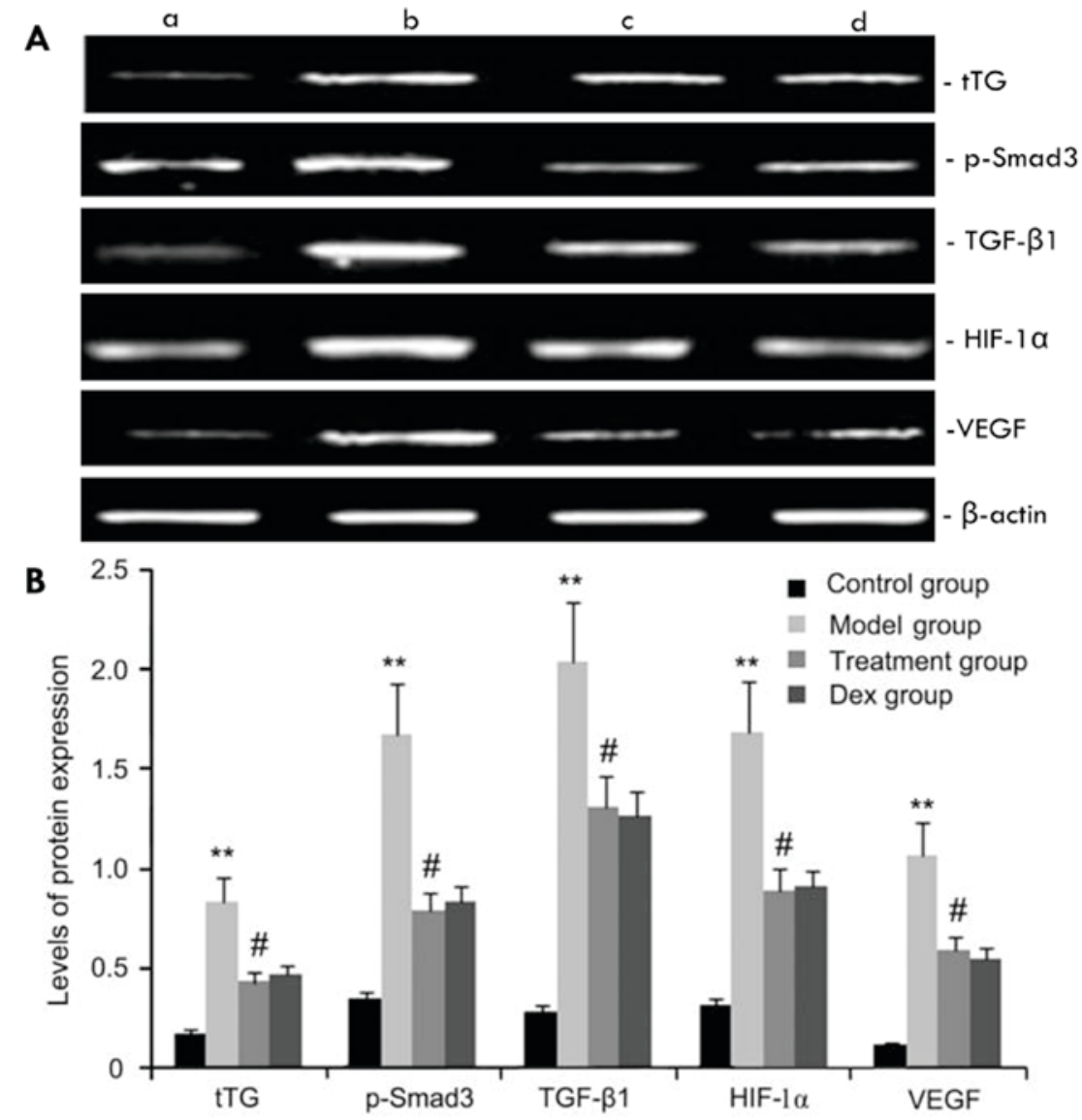

Figure 6. Effects of atorvastatin treatment on tTG, p-Smad3, HIF-1a, VEGF, and TGF- $\beta 1$ protein expression. Mice were treated with atorvastatin or Dex and challenged with OVA (nebulized 2.5\% solution $30 \mathrm{~min} /$ day, 3 days/week for 6 weeks). tTG, p-Smad3, HIF-1 $\alpha$, VEGF and TGF- $\beta 1$ protein were measured by western blot analysis. (A) Representative western blots showing the protein expression levels of tTG, p-Smad3, HIF-1 $\alpha$, VEGF and TGF- $\beta 1$ in the four groups of mice. Lanes: a, control group; b, model group; c, treatment group; d, Dex group. (B) Densitometrically quantified protein levels of tTG, p-Smad3, HIF-1 $\alpha$, VEGF and TGF- $\beta 1$ in the four groups. Values are expressed as the mean \pm standard deviation of one experiment consisting of three replicates. The experiments were performed in triplicates. ${ }^{* *} \mathrm{P}<0.05$, vs. control group; ${ }^{*} \mathrm{P}<0.05$ vs. model group. Dex, dexamethasone; VEGF, vascular endothelial growth factor; TGF- $\beta$, transforming growth factor $\beta$; HIF, hypoxia-inducible factor; tTG, tissue transglutaminase; p-Smad3, phosphorylated Smad3.

Effects of atorvastatin on $t T G, p-S m a d 3, H I F-1 \alpha, V E G F$ and $T G F-\beta 1$ protein expression. The expression levels of $\mathrm{tTG}, \mathrm{p}-\mathrm{Smad} 3, \mathrm{HIF}-1 \alpha$, VEGF and TGF- $\beta 1$ protein in mouse pulmonary tissue were evaluated by western blot analysis. As shown in Fig. 6, compared with the control group, the OVA-challenged group showed increases in tTG, p-Smad3, HIF-1 $\alpha$, VEGF and TGF- $\beta 1$ protein levels, which were inhibited by atorvastatin. However, no significant difference was observed between the atorvastatin group and the Dex group $(\mathrm{P}>0.05)$.

Atorvastatin upregulates Nrf2 and NQO1 expression, decreases ROS generation, and increases GSH levels in the lung. Next, the levels of Nrf2 and NQO1 expression, ROS generation and GSH levels we determined in the mouse model of chronic allergic airway disease. As shown in Fig. 7, in OVA-treated animals, Nrf2 and NQO1 expression levels in lung tissue were significantly decreased, ROS activity was significantly increased and GSH activity was significantly decreased at $48 \mathrm{~h}$ after the last OVA inhalation compared with the levels in the control mice. Administration of atorvastatin and Dex significantly increased Nrf2 and NQO1 expression levels in lung tissues, inhibited ROS generation and increased GSH activity. However, no significant difference was observed between the atorvastatin group and the Dex group $(\mathrm{P}>0.05)$.

Atorvastatin suppresses $\alpha$-SMA expression in lung tissues of asthmatic mice. To investigate the effect of atorvastatin treatment on $\alpha$-SMA expression in lung tissues of asthmatic mice, $\alpha$-SMA expression was measured by immunohistochemistry. As shown in Fig. 8, OVA inhalation markedly increased $\alpha$-SMA expression in lung tissues of asthmatic mice, while the administration of atorvastatin and Dex significantly decreased the $\alpha$-SMA expression in lung tissues. However, no significant difference was observed between the atorvastatin group and the Dex group $(\mathrm{P}>0.05)$.

Effect of atorvastatin on lung collagen deposition and Hyp content in asthmatic mouse lungs. Due to prolonged inflammation in chronic asthma, increased collagen deposition is a hallmark of airway remodeling. To evaluate the degree of collagen deposition, lung sections from mice were stained with Masson's trichrome (Fig. 9A). In addition the Hyp content was measured. As shown in Fig. 9, the accumulation of collagen and Hyp content in lung tissues was markedly increased in the OVA-challenged mice compared with that in PBS-challenged mice. Treatment with Dex or atorvastatin 
A
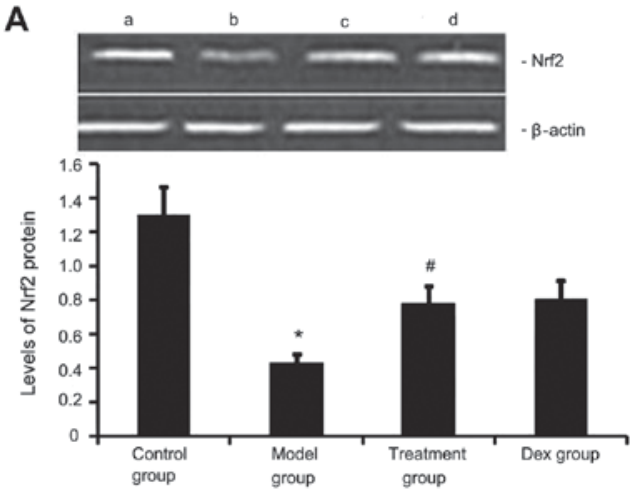

C

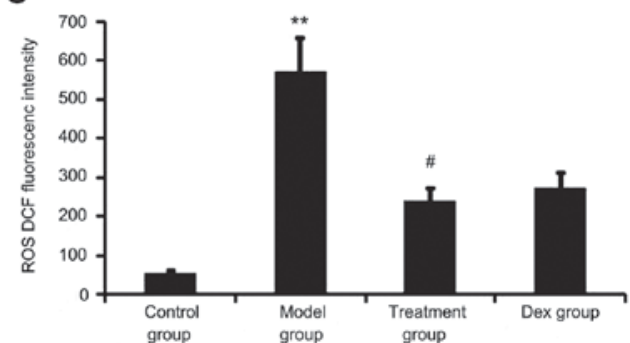

B
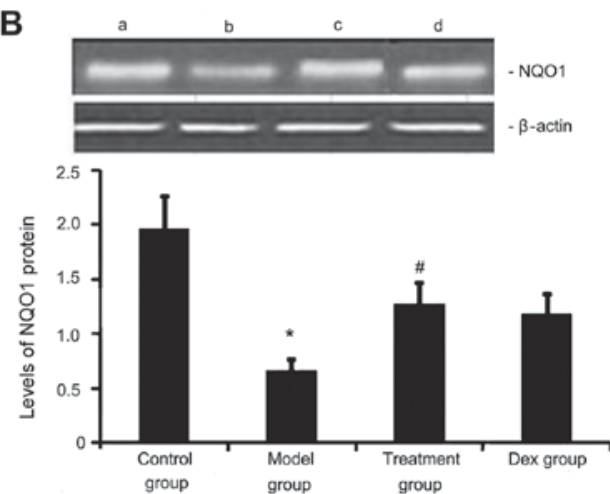

D

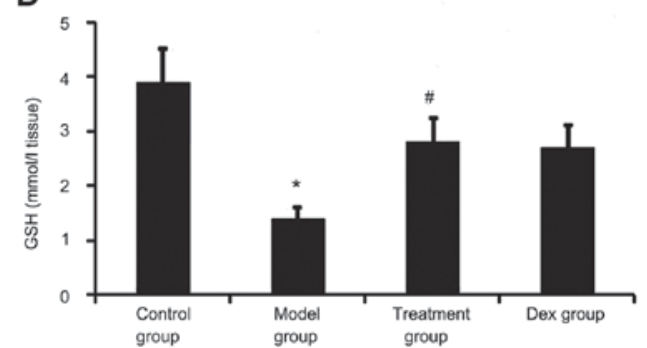

Figure 7. Effects of atorvastatin treatment on Nrf2 and NQO1 expression as well as ROS and GSH activities in the lung tissues of asthmatic mice. Mice were treated with atorvastatin or Dex and challenged with ovalbumin (nebulized 2.5\% solution $30 \mathrm{~min} / \mathrm{day}, 3$ days/week for 6 weeks). The expression of (A) Nrf2 and (B) NQO1 protein was measured by western blot analysis. Representative western blots showing the protein expression levels of Nrf2 and NQO1 in the four groups of mice are shown in the upper panel. Lanes: a, control group; b, model group; c, treatment group; d, DEX group. Densitometrically quantified protein expression levels are shown in the lower panel. The activities of (C) ROS and (D) GSH in lung tissues were also measured. Values are expressed as the mean \pm standard deviation of one experiment consisting of three replicates. The experiments were performed in triplicate. ${ }^{*} \mathrm{P}<0.05,{ }^{* *} \mathrm{P}<0.01$ vs. control group; ${ }^{*} \mathrm{P}<0.05$ vs. model group. NQO1, NADPH quinine oxidoreductase; Nrf2, nuclear factor erythroid 2-related factor 2; ROS, reactive oxygen species; GSH glutathione; Dex, dexamethasone.

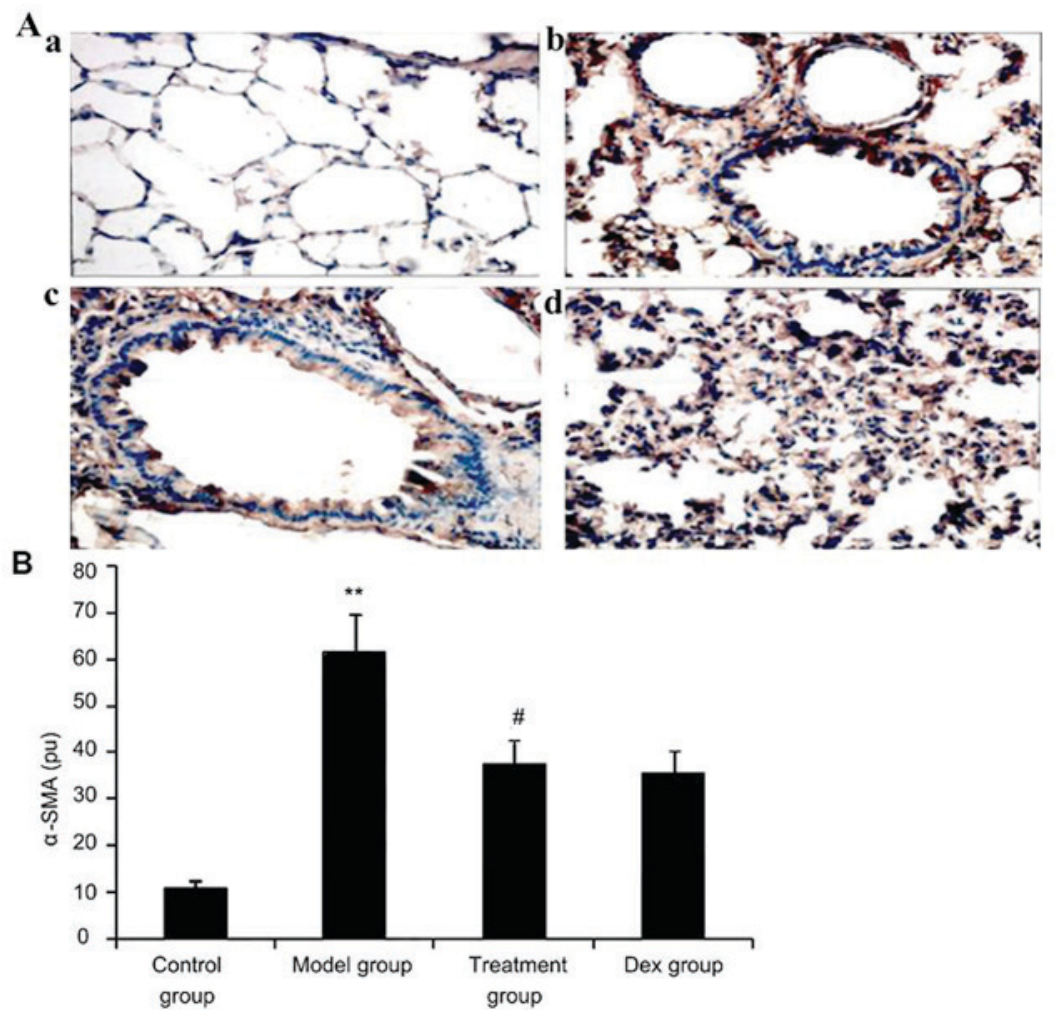

Figure 8. Effect of atorvastatin treatment on $\alpha$-SMA expression in the lung tissues of asthmatic mice. Mice were treated with atorvastatin or DEX and challenged with ovalbumin (nebulized 2.5\% solution $30 \mathrm{~min} / \mathrm{day}, 3$ days/week for 6 weeks), and $\alpha$-SMA expression in lung tissues was determined using immunohistochemistry. (A) Representative immunostaining images showing cells with positive expression levels of $\alpha$-SMA in the four groups of mice (immunofluorescence staining; magnification, $x 400$. Groups: a, control group; b, model group; $c$, treatment group; d, Dex group). (B) $\alpha$-SMA-positive cells were quantified from the immunohistochemical images to determine the expression of $\alpha$-SMA in lung tissues assayed. Values are expressed as the mean \pm standard deviation of one experiment consisting of three replicates. The experiments were performed in triplicate. ${ }^{* *} \mathrm{P}<0.05$, vs. control group; ${ }^{\#} \mathrm{P}<0.05$ vs. model group. Dex, dexamethasone; SMA, smooth muscle actin; pu, positive units. 
A
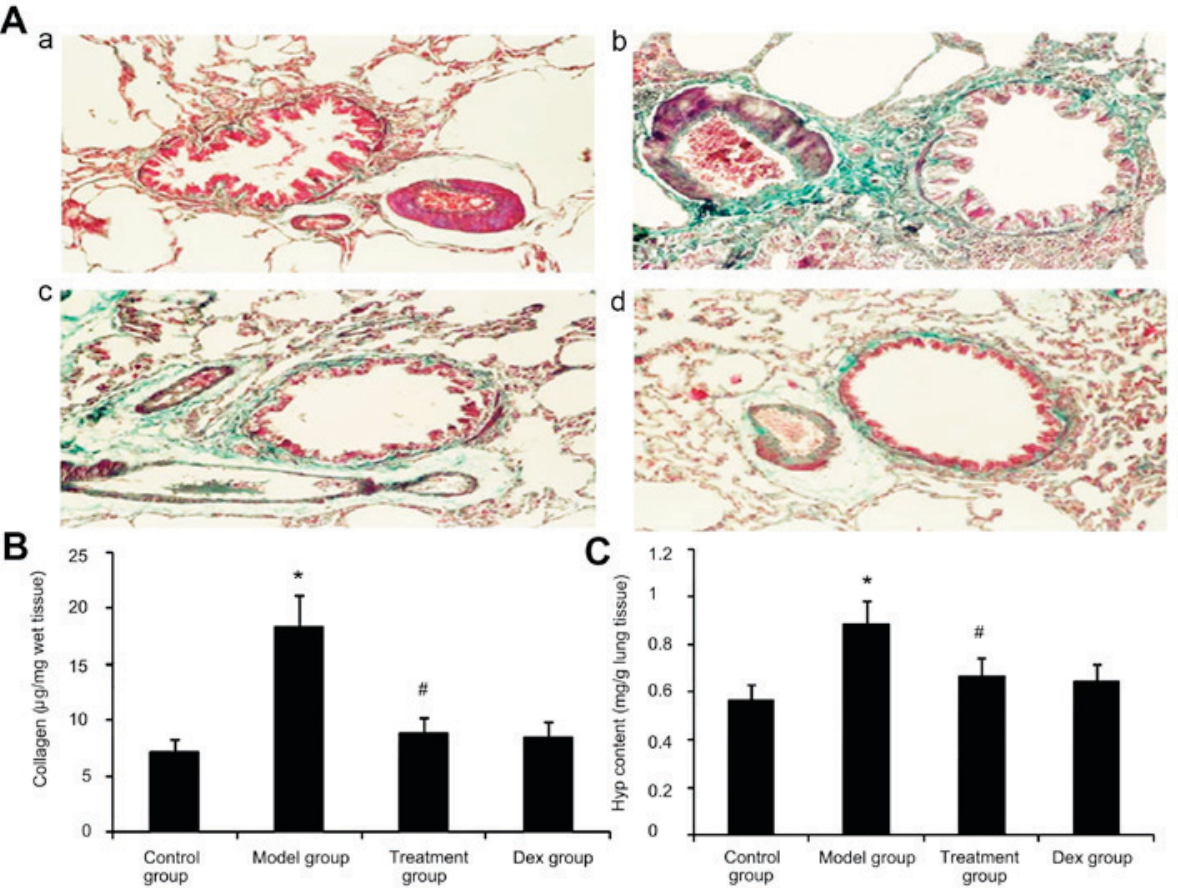

Figure 9. Effect of atorvastatin treatment on collagen deposition in the lung tissues of asthmatic mice. Mice were nebulized with PBS or ovalbumin and treated with atorvastatin or Dex during the nebulization. (A) For the purpose of assessing collagen deposition, tissue sections of lungs from mice were stained with Masson's trichrome for assessing the Masson-stained area/length of the bronchial basal membrane in the four groups of mice (magnification, $\mathrm{x} 400$ ). Groups: a, control group; b, model group; c, treatment group; d, Dex group. (B) The Sircol assayed collagen deposition levels in the four groups of mice. (C) The hydroxyproline content in the four groups was determined. Values are expressed as the mean \pm standard deviation of one experiment consisting of three replicates. The experiments were performed in triplicates. ${ }^{*} \mathrm{P}<0.05$ vs. control group; ${ }^{*} \mathrm{P}<0.05$ vs. model group. Dex, dexamethasone.

A
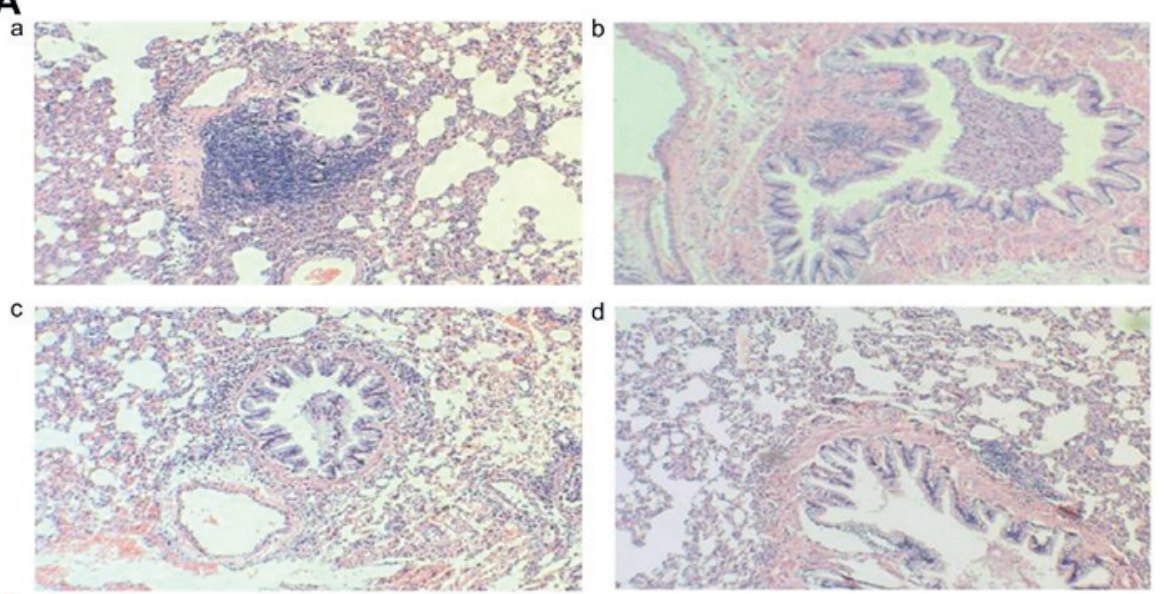

B
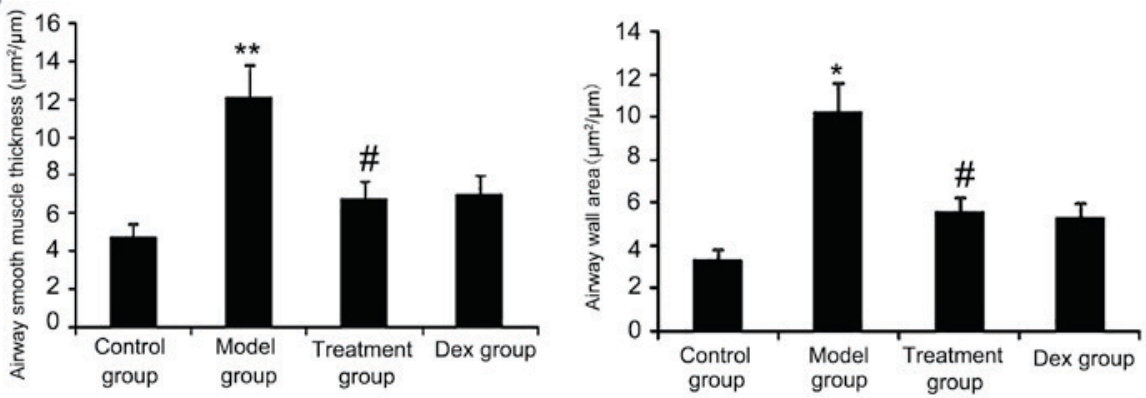

Figure 10. Atorvastatin decreases the airway wall area and airway smooth muscle thickness in mice. The mice were treated with atorvastatin or Dex and challenged with ovalbumin (nebulized 2.5\% solution $30 \mathrm{~min} /$ day, 3 days/week for 6 weeks). For the purpose of assessing the airway wall area and airway smooth muscle thickness, tissue sections of the lungs of the mice were stained with H\&E (magnification, $\mathrm{x} 400$ ). (A) Representative images of the H\&E-stained lung sections from the four experimental groups are shown: a, control group; b, model group; c, treatment group; d, Dex group. (B) Airway smooth muscle thickness and airway wall area were determined using Image Pro-Plus software 6.0. Values are expressed as the mean \pm standard deviation of one experiment consisting of three replicates. The experiments were performed in triplicate. ${ }^{*} \mathrm{P}<0.05,{ }^{* *} \mathrm{P}<0.01$ vs. control group; ${ }^{*} \mathrm{P}<0.05$ vs. model group. Dex, dexamethasone; H\&E, hematoxylin and eosin. 


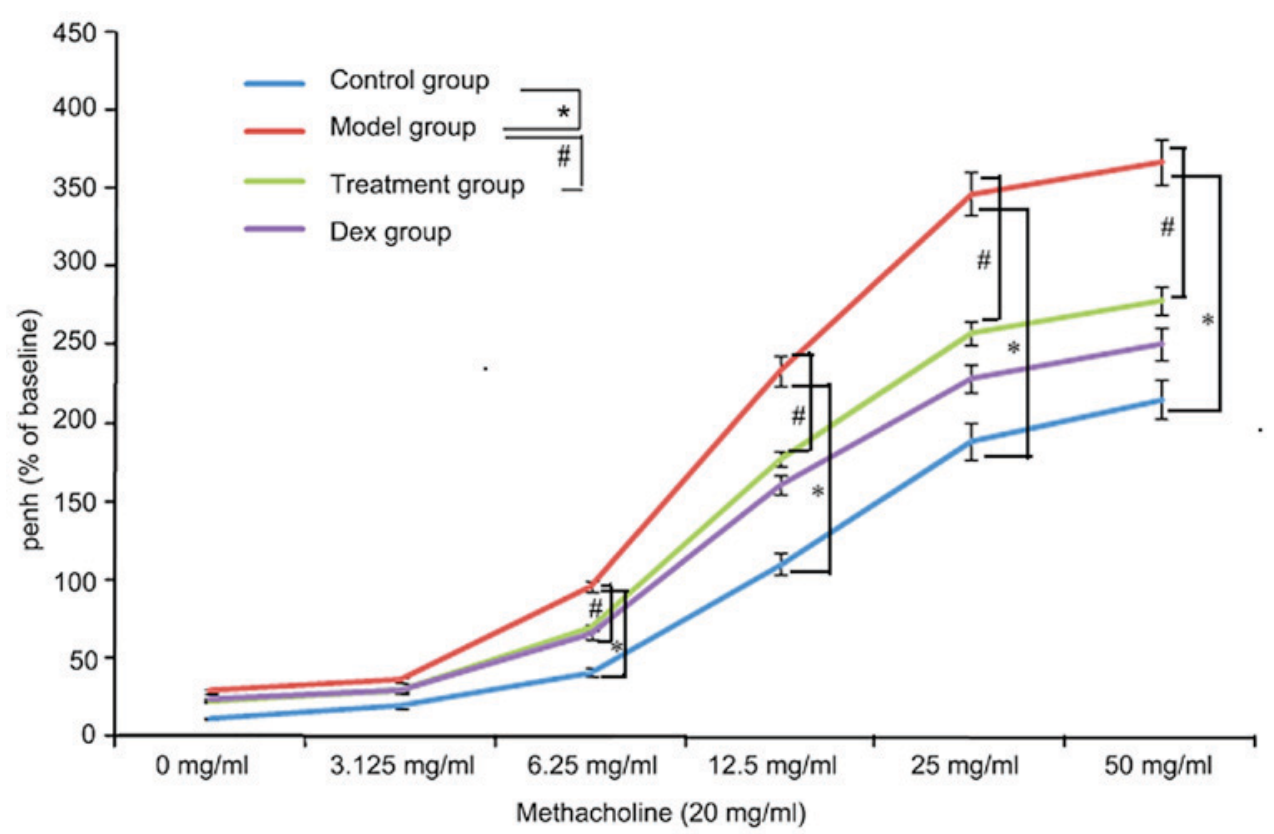

Figure 11. Effects of atorvastatin on AHR in ovalbumin-challenged mice. The AHR to methacholine was measured with a Buxco apparatus and was reported as the change in Penh. Values are expressed as the mean \pm standard deviation of one experiment consisting of three replicates. The experiments were performed in triplicate. ${ }^{~} \mathrm{P}<0.05$ between control and model groups; ${ }^{~} \mathrm{P}<0.05$ between model and treatment groups. Penh, enhanced minute pause; Dex, dexamethasone; AHR, airway hyperresponsiveness.

significantly reduced this increase $(\mathrm{P}<0.05)$. No significant difference was observed between the atorvastatin group and the Dex group $(\mathrm{P}>0.05)$.

Atorvastatin reduces the airway wall area and ASM thickness. The results of the present study suggested that ASM thickness may be associated with the severity of asthma. Therefore, the airway wall area and ASM thickness in treated animals were measured. As shown in Fig. 10, OVA-challenged mice showed a significantly increased airway wall area and ASM thickness compared with that in the control group $(\mathrm{P}<0.05)$ and the treatment with Dex or atorvastatin significantly reduced this increase $(\mathrm{P}<0.05)$. No significant difference was observed between the atorvastatin and the Dex groups $(\mathrm{P}>0.05)$. The airway wall area and ASM thickness in mice treated with atorvastatin or Dex without OVA sensitization showed no significant difference compared with the control group.

Atorvastatin reduces AHR. To investigate the effects of atorvastatin on AHR, the physiological effect of the MCh administration on AHR was examined. As shown in Fig. 11, the Penh value of OVA-challenged mice was increased, as assessed by MCh administration $(20 \mathrm{mg} / \mathrm{ml})$. However, the increased Penh response to MCh challenge in OVA-challenged mice was effectively reduced by atorvastatin administration.

\section{Discussion}

In the present study, a range of asthma-associated symptoms was observed in the OVA-induced asthma mouse model. These symptoms included altered levels of endurance, irritability, shortness of breath, lips cyanosis, mouth breathing and astasia. Pathologic observations indicated that the trachea and a large number of inflammatory cells were present around alveoli and blood vessels. In the acetylcholine provocation test, with increased acetylcholine concentrations, the expiratory peak in the asthma group is significantly decreased (27). This indicates that the airway resistance is increased with elevated acetylcholine concentrations, indicating the presence of bronchial hyperresponsiveness (BHR) in the model. Lung tissue pathological biopsy showed bronchial wall thickening and tracheal mucous membrane damage. Consequently, the model used in the present study complies with the evaluation criteria of successful bronchial asthma airway remodeling (17).

Bronchial remodeling is closely associated with tracheal inflammation as a result of chronic airway inflammation (28). This is caused by excessive repair of chronic repetitive injuries to airway walls and is characterized by variation in epithelial cell morphology, an increase in the size of submucosal glands, hyperplasia and hypertrophy of ASM, and hyperplasia of muscle fibroblasts (29). In the present study, the number of pulmonary inflammatory cells, the generation of pro-inflammatory mediators (IL-8, IL-17 and IL-13), and the expression levels of intrapulmonary MMP-9 and TGF- $\beta 1$ were all elevated. Moreover, significant collagen deposition on the intrapulmonary bronchial wall, bronchial remodeling and bronchial wall thickening led to BHR.

Glucocorticoids are currently the optimal option to control asthmatic inflammation (30). They alleviate trachea inflammation as well as the release of inflammatory mediators (31), and inhibit or reverse airway remodeling directly or indirectly through alleviating the inflammation (32). Consequently, in the present study, Dex treatment was applied in the positive control group. The results of the present study showed that Dex significantly inhibited trachea inflammation, reduced collagen deposition on the bronchial wall, alleviated bronchial wall 
thickening and improved bronchial remodeling in mice with bronchial asthma.

Atorvastatin is a HMG-CoA reductase inhibitor (33). The drug is the most widely used and effective lipid-lowering drug. In addition to the lipid-lowering effect, statins also has anti-inflammatory, immunomodulatory and anti-BHR activities and inhibits cell proliferation (33-37). The above effects are reflected in the following aspects: Simvastatin can decrease the amount of BALF cells in asthmatic mice and also reduces the levels of IL-4, IL-13 and TNF- $\alpha$ and the serum immunoglobulin E levels (33). Moreover, its anti-inflammatory effects promote decreased airway resistance, improve lung compliance and inhibit the generation and release of T-helper cell type 1 (Th1) and Th2 factors $(35,36)$. However, the specific mechanism remains elusive. In the model used in the present study, atorvastatin reduced the aggregation of pulmonary inflammatory cells, decreased intrapulmonary inflammation, increased the activity of antioxidant enzymes, decreased the intrapulmonary oxidative stress response and reduced the expression of genes involved in the stimulation of intrapulmonary collagen deposition, thus improving bronchial remodeling. Its effects were not significantly different from those of Dex.

tTG participates in fibrotic processes in the lung, kidney, liver and other visceral organs $(6,38)$. TGF- $\beta$ is generally considered as one of the most critical cytokines during fibrosis formation and development (39). It is a master regulator of fibrosis formation and the strongest pro-fibrotic factor. tTG can cause TGF- $\beta 1$-linking protein to dissociate TGF- $\beta 1$ from the ECM and activate it (40). The activated TGF- $\beta 1$ can also increase tTG gene expression, forming a positive feedback loop to increase the expression of collagen and fibronectin, and promote the occurrence and development of fibrosis (41). After pulmonary fibrosis was induced by bleomycin in tTG knockout mice, the expression of MMP-9 decreased, thus reducing the generation of hydroxyproline and collagen, and clearly relieving pulmonary fibrosis (41). In the present study, OVA significantly promoted the increase of tTG levels in the bronchial asthma mouse model, further increasing the activity of Smad3/TGF- $\beta 1$ signaling, MMP-9 levels and collagen deposition to aggravate airway remodeling. However, atorvastatin inhibited the expression of tTG, reduced the activity of Smad3/TGF- $\beta 1$ signaling and MMP-9 levels, decreased collagen deposition and improved bronchial remodeling.

The transcription factor NF- $\mathrm{BB}$ is at the core of the inflammatory reaction (19). It promotes the transcription and release of inflammatory factors (19). Signal transduction occurs from the interaction of TREM-1 with the SH2 structural domain of the Syk tyrosine kinase. Syk phosphorylates CBL and growth factor receptor-bound protein 2 to activate mitogen-activated protein kinase, $\mathrm{NF}-\kappa \mathrm{B}$ and other transcription factors, promoting the expression and secretion of inflammatory cytokines (12-42). In the present study study, OVA was found to promote the expression of TREM-1 of mice with bronchial asthma to further upregulate the activity of $\mathrm{NF}-\kappa \mathrm{B}$ p65, accelerate the bronchial inflammatory reaction of mice with bronchial asthma and aggravate bronchial wall remodeling, and this was inhibited by atorvastatin.

The Nrf2 pathway is one of the most important cellular resistance mechanisms in response to oxidative stress damage in a variety of tissues and organs (43). NQO1 is a downstream antioxidant enzyme in the Nrf2 pathway (44). When a cell is subjected to oxidative stress, Nrf2 interacts with kelch-like $\mathrm{ECH}$-associated protein 1 to perform uncoupling prior to being activated and transported into the cell nucleus. Nrf2 then binds to antioxidant response elements in gene promoters to regulate the expression of the downstream antioxidant enzyme NQO1, thus enhancing the tolerance of cells to oxidative stress $(45,46)$. The pathogenesis of asthma is known to involve ROS generation and loss of antioxidant defenses (43). A widely recognized central feature of asthma and other airway inflammatory diseases are alterations in alveolar and lung GSH metabolism (45). In the present study, atorvastatin increased the expression of Nrf2, NQO1 and antioxidant enzyme GSH, reduced the expression of ROS and improved bronchial remodeling in a mouse model.

MMP-9 promotes the synthesis of collagen IV and V as well as laminin and elastin to form basement membrane ECM, and the release of a variety of growth and differentiation factors (such as TNF- $\alpha$, VEGF and TGF- $\beta$ ), thus promoting tissue fibrosis, vascular cell proliferation and tissue remodeling (47-49). TIMP-1 is a specific inhibitor of MMP-9 and blocks substrate degradation (48). In the present study, atorvastatin inhibited the activity of MMP-9, reduced the expression of VEGF and TGF- $\beta$, decreased collagen deposition in bronchial airways in a mouse model of bronchial asthma and improved bronchial remodeling in asthmatic mice. However, atorvastatin had a lower impact on TIMP-1 levels than on the other mediators examined.

TGF- $\beta 1$ signaling has been identified as one of the important mechanisms in bronchial remodeling (50). TGF- $\beta 1$ expression is positively correlated to the number of fibroblasts and bronchial basement membrane thickness, as well as asthma severity. Smad3 promotes the expression of TGF- $\beta 1$ and bronchial remodeling (51). In the present study, atorvastatin inhibited the phosphorylation of Smad3 and reduced the expression of TGF- $\beta 1$.

VEGF participates in inflammatory cell movement, maintains cell survival and promotes the expression of TGF- $\beta 1$ (52). The expression of VEGF under low-oxygen conditions is regulated by HIF-l $\alpha$ (53). In the present study, the expression of HIF-1 $\alpha$ in the lungs of bronchial asthmatic mice increased and is the likely reason for the elevated expression of VEGF and TGF- $\beta 1$ as well as the aggravation of bronchial remodeling in mice with bronchial asthma. Furthermore, atorvastatin treatment blocked the expression of HIF-1 $\alpha$, and reduced the expression of VEGF and TGF- $\beta 1$.

$\alpha$-SMA is the predominant isoform of actin within vascular smooth-muscle cells and has an important role in bronchial remodeling; it is also a major marker of ASM, with reduced levels reflecting changes of ASM quantity and shrinking (54). The present study showed that atorvastatin decreased $\alpha$-SMA levels in the mouse model of bronchial asthma.

Hyp is a major component of the protein collagen (55). Hyp and proline have key roles in collagen stability (54). The increase in bronchial wall thickness in asthma is associated with the deposition of collagen and other matrix proteins, such as fibronectin, cytotactin, tendon protein and laminin. Airway wall thickening is correlated with clinically severe asthma (55) and is a prominent feature of lung tissue of patients with fatal asthma. In the present study, the Hyp content and deposition of 
collagen in asthmatic mouse lungs was increased, which was suppressed by atorvastatin.

AHR is positively correlated with the severity of bronchial remodeling and asthma (53). A reduction in AHR is an important indicator of therapeutic benefit. The results of the present study indicated that atorvastatin decreased AHR by improving bronchial remodeling. Bronchial resistance in the atorvastatin group was obviously lower than that in the OVA group, indicating that atorvastatin reduces the BHR of asthmatic mice.

In conclusion, the present study demonstrated that atorvastatin inhibited asthma-associated airway wall remodeling through mechanisms involving a decrease in the expression of tTG and TREM-1 as well as modulation of the Nrf2 signaling pathway in the lung. This suggests the possibility of further developing atorvastatin as a candidate for the prevention and treatment of airway remodeling in asthma.

\section{References}

1. Befekadu E, Onofrei C and Colice GL: Tiotropium in asthma: A systematic review. J Asthma Allergy 7: 11-21, 2014

2. Roche WR, Beasley R, Williams JH and Holgate ST: Subepithelial fibrosis in the bronchi of asthmatics. Lancet 1: 520-524, 1989

3. Aikawa T, Shimura S, Sasaki H, Ebina M and Takishima T: Marked goblet cell hyperplasia with mucus accumulation in the airways of patients who died of severe acute asthma attack. Chest 101: 916-921, 1992.

4. Wiggs BR, Bosken C, Paré PD, James A and Hogg JC: A model of airway narrowing in asthma and in chronic obstructive pulmonary disease. Am Rev Respir Dis 145: 1251-1258, 1992.

5. Nakaoka H, Perez DM, Baek KJ, Das T, Husain A, Misono K, Im MJ and Graham RM: Gh: A GTP-binding protein with transglutaminase activity and receptor signaling function. Science 264: 1593-1596, 1994.

6. Lorand L and Graham RM: Transglutaminases: Crosslinking enzymes with pleiotropic functions. Nat Rev Mol Cell Biol 4 140-156, 2003.

7. Iismaa SE, Mearns BM, Lorand L and Graham RM: Transglutaminases and disease: Lessons from genetically engineered mouse models and inherited disorders. Physiol Rev 89: 991-1023, 2009.

8. Griffin M, Casadio R and Bergamini CM: Transglutaminases: Nature's biological glues. Biochem J 368: 377-396, 2002.

9. Shweke N, Boulos N, Jouanneau C, Vandermeersch S, Melino G, Dussaule JC, Chatziantoniou C, Ronco P and Boffa JJ: Tissue transglutaminase contributes to interstitial renal fibrosis by favoring accumulation of fibrillar collagen through TGF-beta activation and cell infiltration. Am J Pathol 173: 631-642, 2008.

10. Radsak MP, Salih HR, Rammensee HG and Schild H: Triggering receptor expressed on myeloid cells-1 in neutrophil inflammatory responses: Differential regulation of activation and survival. J Immunol 172: 4956-4963, 2004.

11. Bouchon A, Dietrich J and Colonna M: Cutting edge: Inflammatory responses can be triggered by TREM-1, a novel receptor expressed on neutrophils and monocytes. J Immunol 164: 4991-4995, 2000.

12. Bouchon A, Facchetti F, Weigand MA and Colonna M: TREM-1 amplifies inflammation and is a crucial mediator of septic shock. Nature 410: 1103-1107, 2001

13. Fassett RG, Robertson IK, Ball MJ, Geraghty DP and Coombes JS: Effects of atorvastatin on biomarkers of inflammation in chronic kidney disease. Clin Nephrol 81: 75-85, 2014.

14. Simpson RJ, Signorovitch J, Ramakrishnan K, Ivanova J, Birnbaum $\mathrm{H}$ and Kuznik A: Cardiovascular and economic outcomes after initiation of atorvastatin versus simvastatin in an employed population stratified by cardiovascular risk. Am J Ther 18 436-448, 2011

15. Balli U, Keles GC, Cetinkaya BO, Mercan U, Ayas B and Erdogan D: Assessment of vascular endothelial growth factor and matrix metalloproteinase-9 in the periodontium of rats treated with atorvastatin. J Periodontol 85: 178-187, 2014

16. Feldman C: Statins for non-cystic fibrosis bronchiectasis. Lancet Respir Med 2: 431-432, 2014.
17. Jain W, Kitagaki K, Businga T, Hussain I, George C, O'shaughnessy P and Kline JN: CpG-oligodeoxynucleotides inhibit airway remodeling in a murine model of chronic asthma. J Allergy Clin Immunol 110: 867-872, 2002.

18. Livak KJ and Schmittgen TD: Analysis of relative gene expression data using real-time quantitative PCR and the 2(-Delta Delta C(T)) Method. Methods 25: 402-408, 2001

19. Liu MW, Wang YH, Qian CY and Li H: Xuebijing exerts protective effects on lung permeability leakage and lung injury by upregulating Toll-interacting protein expression in rats with sepsis. Int J Mol Med 34: 1492-1504, 2014.

20. Mizutani N, Nabe T and Yoshino S: IL-17A promotes the exacerbation of il-33-induced airway hyperresponsiveness by enhancing neutrophilic inflammation via CXCR2 signaling in mice. J Immunol 192: 1372-1384, 2004.

21. Entezari M, Javdan M, Antoine DJ, Morrow DM, Sitapara RA, Patel V, Wang M, Sharma L, Gorasiya S, Zur M, et al: Inhibition of extracellular HMGB1 attenuates hyperoxia-induced inflammatory acute lung injury. Redox Biol 2: 314-322, 2014.

22. Wen H, Gwathmey JK and Xie LH: Oxidative stress-mediated effects of angiotensin II in the cardiovascular system. World J Hypertens 2: 34-44, 2012.

23. Wei B, Shang YX, Li M, Jiang J and Zhang H: Cytoskeleton changes of airway smooth muscle cells in juvenile rats with airway remodeling in asthma and the RhoA/ROCK signaling pathway mechanism. Genet Mol Res 13: 559-569, 2014.

24. Jamall IS, Finelli VN and Que Hee SS: A simple method to determine nanogram levels of 4-hydroyproline in biological tissues. Anal Biochem 112: 70-75, 1981.

25. Bai A,Eidelman DH,Hogg JC,James AL, Lambert RK,Ludwig MS, Martin J, McDonald DM, Mitzner WA, Okazawa M, et al: Proposed nomenclature for quantifying subdivisions of the bronchial wall. J Appl Physiol (1985) 77: 1011-1014, 1994.

26. Takeda N, Kondo M, Ito S, Ito Y, Shimokata K and Kume H: Role of RhoA inactivation in reduced cell proliferation of human airway smooth muscle by simvastatin. Am J Respir Cell Mol Biol 35: 722-729, 2006.

27. Mookerjee I, Solly NR, Royce SG, Tregear GW, Samuel CS and Tang ML: Endogenous relaxin regulates collagen deposition in an animal model of allergic airway disease. Endocrinology 147: 754-761, 2006.

28. Davies DE and Holgate ST: Asthma: The importance of epithelial mesenchymal communication in pathogenesis. Inflammation and the airway epithelium in asthma. Int J Biochem Cell Biol 34: 1520-1526, 2002.

29. Tang ML, Wilson JW, Stewart AG and Royce SG: Airway remodelling in asthma: Current understanding and implications for future therapies. Pharmacol Ther 112: 474-488, 2006.

30. Barnes PJ: Anti-inflammatory actions of glucocorticoids: Molecular mechanisms. Clin Sci (Lond) 94: 557-572,1998.

31. Boulet LP, Turcotte H, Laviolette M, Naud F, Bernier MC, Martel S and Chakir J: Airway hyperresponsiveness, inflammation, and subepithelial collagen deposition in recently diagnosed versus long-standing mild asthma. Influence of inhaled corticosteroids. Am J Respir Crit Care Med 162: 1308-1313, 2000.

32. Irwin RS and Richardson ND: Side effects with inhaled corticosteroids: The physician's perception. Chest 130 (1 Suppl): 41S-53S, 2006

33. Johnson BA, Iacono AT, Zeevi A, McCurry KR and Duncan SR: Statin use is associated with improved function and survival of lung allografts. Am J Respir Crit Care Med 167: 1271-1278, 2003.

34. McKay A, Leung BP, McInnes IB, Thomson NC and Liew FY: A novel anti-inflammatory role of simvastatin in a murine model of allergic asthma. J Immunol 172: 2903-2908, 2004.

35. Zeki AA, Franzi L, Last J and Kenyon NJ: Simvastatin inhibits airway hyperreactivity: Implications for the mevalonate pathway and beyond. Am J Respir Crit Care Med 180: 731-740, 2009.

36. Chiba Y, Arima J, Sakai H and Misawa M: Lovastatin inhibits bronchial hyperresponsiveness by reducing RhoA signaling in rat allergic asthma. Am J Physiol Lung Cell Mol Physiol 294: L705-L713, 2008.

37. Chiba Y, Sato $S$ and Misawa M: Inhibition of antigen-induced bronchial smooth muscle hyperresponsiveness by lovastatin in mice. J Smooth Muscle Res 44: 123-128, 2008.

38. Sánchez-Lara AC, Elliott J, Syme HM, Brown CA and Haylor JL: Feline chronic kidney disease is associated with upregulation of transglutaminase 2: A collagen cross-linking enzyme. Vet Pathol 52: 513-523, 2015.

39. Sime PJ and O'Reilly KM: Fibrosis of the lung and other tissues: New concepts in pathogenesis and treatment. Clin Immunol 99: 308-319, 2001 
40. Griffin M, Smith LL and Wynne J: Changes in transglutaminase activity in an experimental model of pulmonary fibrosis induced by paraquat. Br J Exp Pathol 60: 653-661, 1979.

41. Olsen KC, Sapinoro RE, Kottmann RM, Kulkarni AA, Iismaa SE, Johnson GV, Thatcher TH, Phipps RP and Sime PJ: Transglutaminase 2 and its role in pulmonary fibrosis. Am J Respir Crit Care Med 184: 699-707, 2011.

42. Genua M, Rutella S, Correale C and Danese S: The triggering receptor expressed on myeloid cells (TREM) in inflammatory bowel disease pathogenesis. J Transl Med 12: 293, 2014.

43. Erlank H, Elmann A, Kohen R and Kanner J: Polyphenols activate $\mathrm{Nrf} 2$ in astrocytes via $\mathrm{H}_{2} \mathrm{O}_{2}$, semiquinones, and quinones. Free Radic Biol Med 51: 2319-2327, 2011.

44. Park JS, Jung JS, Jeong YH, Hyun JW, Le TK, Kim DH, Choi EC and Kim HS: Antioxidant mechanism of isoflavone metabolites in hydrogen peroxide-stimulated rat primary astrocytes: Critical role of hemeoxygenase-1 and NQO1 expression. J Neurochem 119: 909-919, 2011.

45. Hou DX, Korenori Y, Tanigawa S, Yamada-Kato T, Nagai M, He X and He J: Dynamics of Nrf2 and Keap1 in ARE-mediated NQO1 expression by wasabi 6-(methylsulfinyl)hexyl isothiocyanate. J Agric Food Chem 59: 11975-11982, 2011.

46. Lee IS, Lim J, Gal J, Kang JC, Kim HJ, Kang BY and Choi HJ: Anti-inflammatory activity of xanthohumol involves heme oxygenase-1 induction via NRF2-ARE signaling in microglial BV2 cells. Neurochem Int 58: 153-160, 2011.

47. Barbaro MP, Spanevello A, Palladino GP, Salerno FG, Lacedonia D and Carpagnano GE: Exhaled matrix metalloproteinase-9 (MMP-9) in different biological phenotypes of asthma. Eur J Intern Med 25: 92-96, 2014.

48. Possa SS, Charafeddine HT, Righetti RF, da Silva PA, Almeida-Reis R, Saraiva-Romanholo BM, Perini A, Prado CM, Leick-Maldonado EA, Martins MA and Tibério Ide F: Rho-kinase inhibition attenuates airway responsiveness, inflammation, matrix remodeling, and oxidative stress activation induced by chronic inflammation. Am J Physiol Lung Cell Mol Physiol 303: L939-L952, 2012.
49. Yeo NK, Eom DW, Oh MY, Lim HW and Song YJ: Expression of matrix metalloproteinase 2 and 9 and tissue inhibitor of metalloproteinase 1 in nonrecurrent vs recurrent nasal polyps. Ann Allergy Asthma Immunol 111: 205-210, 2013.

50. Che Z, Zhu X, Yao C, Liu Y, Chen Y, Cao J, Liang C and Lu Y. The association between the $\mathrm{C}-509 \mathrm{~T}$ and $\mathrm{T} 869 \mathrm{C}$ polymorphisms of TGF- $\beta 1$ gene and the risk of asthma: A meta-analysis. Hum Immunol 75: 141-150, 2014

51. Baek KJ, Cho JY, Rosenthal P, Alexander LE, Nizet V and Broide DH: Hypoxia potentiates allergen induction of HIF-1 $\alpha$, chemokines, airway inflammation, TGF- $\beta 1$, and airway remodeling in a mouse model. Clin Immunol 147: 27-37, 2013.

52. Mirzoeva S, Franzen CA and Pelling JC: Apigenin inhibits TGF- $\beta$-induced VEGF expression in human prostate carcinoma cells via a Smad2/3- and Src-dependent mechanism. Mol Carcinog 53: 598-609, 2014.

53. Le Cras TD, Acciani TH, Mushaben EM, Kramer EL, Pastura PA, Hardie WD, Korfhagen TR, Sivaprasad U, Ericksen M, Gibson AM, et al: Epithelial EGF receptor signaling mediates airway hyperreactivity and remodeling in a mouse model of chronic asthma. Am J Physiol Lung Cell Mol Physiol 300: L414-L421, 2011

54. Park SJ, Lee KS, Lee SJ, Kim SR, Park SY, Jeon MS, Lee HB and Lee YC: L-2-Oxothiazolidine-4-carboxylic acid or $\alpha$-lipoic acid attenuates airway remodeling: Involvement of nuclear factor- $\kappa \mathrm{B}$ (NF-кB), nuclear factor erythroid 2p45-related factor-2 (Nrf2), and hypoxia-inducible factor (HIF). Int J Mol Sci 13: 7915-7937, 2012.

55. Fuchimoto Y, Kanehiro A, Miyahara N, Koga H, Ikeda G, Waseda K, Tanimoto Y, Ueha S, Kataoka M, Gelfand EW and Tanimoto M: Requirement for chemokine receptor 5 in the development of allergen-induced airway hyperresponsiveness and inflammation. Am J Respir Cell Mol Biol 45: 1248-1255, 2011. 